\title{
Response to Environmental Stresses, Cell-wall Integrity, and Virulence Are Orchestrated Through the Calcineurin Pathway in Ustilago hordei
}

\author{
José Antonio Cervantes-Chávez, ${ }^{1}$ Shawkat Ali, ${ }^{2}$ and Guus Bakkeren ${ }^{1}$ \\ ${ }^{1}$ Agriculture and AgriFood Canada, Pacific Agri-Food Research Centre, Summerland, BC, VOH 1ZO, Canada; ${ }^{2}$ Department \\ of Botany, University of British Columbia, Vancouver, BC, V6T 1Z0, Canada
}

Submitted 9 September 2010. Accepted 20 October 2010.

In eukaryotes, several biological processes are regulated through calcium signaling. Calcineurin is a calcium-calmodulin-regulated serine/threonine phosphatase consisting of catalytic subunit $A$ and regulatory subunit B. Phosphatase activity resides in the catalytic subunit, which activates by dephosphorylation downstream components such as transcription factor Crz1. The importance of this pathway to respond to environmental stress has been explored in several fungal pathogens. The basidiomycete Ustilago hordei causes covered smut of barley. We addressed the role of the $\mathrm{Ca}^{2+}$-calcineurin activated pathway by deleting UhCnal and $U h C n b 1$. These genes were not essential in $U$. hordei but the corresponding mutants displayed a variety of phenotypes when applying environmental stress such as sensitivity to $\mathrm{pH}$, temperature, $\mathrm{H}_{2} \mathrm{O}_{2}$, mono- and divalent cations; and to genotoxic, acid, or oxidative stresses. Cell-wall integrity was compromised and mutants displayed altered cell morphologies. Mating was delayed but not abolished, and combined sensitivities likely explained a severely reduced virulence toward barley plants. Expression analyses revealed that response to salt stress involved the induction of membrane ATPase genes UhEna1 and UhEna2, which were regulated through the calcineurin pathway. Upregulation of UhFKS1, a 1,3- $\beta$-D-glucan synthase gene, correlated with the increased amount of 1,3- $\beta$-D-glucan in the calcineurin mutants grown under salt stress.

Calcium is an important ubiquitous second messenger that functions in signaling pathways in eukaryotes. In multicellular organisms, signaling through calcium regulates physiological processes as diverse as muscle contraction, motility, programmed cell death, cell division, differentiation, and chromatin remodeling (Carafoli 2005). In the fungal kingdom, this pathway is involved in morphogenesis, circadian rhythm, cell cycle progression, stress response, and virulence (Cyert 2003; Kraus and Heitman 2003; Miyakawa and Mizunuma 2007; Stie and Fox 2008). Upon increase of intracellular levels of calcium, signaling pathways are activated through the action of two calcium-binding proteins: calmodulin and calcineurin.

Corresponding author: G. Bakkeren; Telephone: 250-494-6368; Fax: 250494-0755; E-mail: guus.bakkeren@agr.gc.ca

* The $\boldsymbol{e}$-Xtra logo stands for "electronic extra" and indicates that six supplementary figures and two supplementary tables are published online.

CHer Majesty the Queen in Right of Canada, as represented by the MInister of Agriculture and Agri-Food Canada
Calcineurin is a highly conserved serine/threonine phosphatase also knows as phosphatase $2 \mathrm{~B}$. The inactive protein is a heterodimer formed by one catalytic subunit A (Cna) and one regulatory subunit $\mathrm{B}(\mathrm{Cnb})$. The enzyme is activated after the interaction of the catalytic subunit with calmodulin. This association produces conformational changes in the catalytic subunit leading to release of its active site from the autoinhibitory regulatory domain (Kissinger et al. 1995). Specific and strong inhibitors of calcineurin phosphatase are the immunosuppressive drugs cyclosporine A (CsA) and FK506 (tracolimus), which bind irreversibly to the immunophilins cyclophilin or FKB12, respectively, resulting in a ternary complex between calcineurin with CsA-cyclophilin or FK506-FKB12 (Matsuda and Koyasu 2000). These complexes inhibit the phosphatase function, thereby preventing the activation of one of the key downstream effectors of this pathway, the transcription factor Crz1 (Cyert 2001; Fox et al. 2001; Karababa et al. 2006). Calcineurin-dependent dephosphorylation of Crz1 causes its nuclear import and, through its $\mathrm{C} 2 \mathrm{H} 2$ zinc finger domain, Crz1 binds to the calcineurin-dependent response element (CDRE) present in calcineurin-responsive genes, thereby activating transcription (Karababa et al. 2006; Matheos et al. 1997; Stathopoulos and Cyert 1997).

In the yeast Saccharomyces cerevisiae, mutants defective in this pathway are not able to grow at alkaline $\mathrm{pH}$, nor in the presence of high concentrations of $\mathrm{Na}^{+}, \mathrm{Li}^{+}$, or $\mathrm{Mn}^{2+}$ ions. However, under standard growing conditions, the function of this pathway is dispensable (Matheos et al. 1997; Mendoza et al. 1996). Similarly, in the human pathogens Candida albicans, Aspergillus fumigatus, and Cryptococcus neoformans, the calcineurin pathway regulates not only growth at alkaline $\mathrm{pH}$ or in the presence of some cations but also is involved in virulence (Bader et al. 2003; Cramer et al. 2008; Fox et al. 2001; Karababa et al. 2006; Odom et al. 1997; Steinbach et al. 2006). Similar effects on virulence and pathogenicity were described in the plant pathogens Sclerotinia sclerotiorum, Botrytis cinerea, and Magnaporthe grisea for mutants defective in this signaling pathway (Harel et al. 2006; Schumacher et al. 2008; Zhang et al. 2009). Recently, the relationship of calcineurin and virulence was addressed in Ustilago maydis, where mutants in the catalytic subunit (ucnl) were severely reduced in virulence toward maize plants (Egan et al. 2009). Another physiological process regulated through this pathway, at least in A. parasiticus, is the synthesis of secondary metabolites (Chang 2008).

We are interested in the possible roles the calcineurin phosphatase catalytic ( $\mathrm{Cnal}$ ) and regulatory $(\mathrm{Cnbl})$ subunits have by interrupting calcium signaling through deletion of the respec- 
tive genes and investigating resulting pleiotropic effects in the plant-pathogenic fungus $U$. hordei. Ustilago spp. have become the paradigm for basidiomycete plant pathogens, with $U$. maydis leading the way. However, in comparison, the close relative $U$. hordei has some additional unique properties such as single genetic elements which can elicit specific host resistance (socalled "avirulence genes") (Linning et al. 2004) and an RNAi machinery (which $U$. maydis lacks) (Laurie et al. 2008). The dimorphic fungus $U$. hordei is a pathogen to small grain cereals such as barley and oat, generally found in nature as black pigmented masses of teliospores on infected ears of the host (Fisher and Holton 1957). The fungus has a worldwide distribution, causing considerable losses due to decreased yield and to contamination of healthy seed with teliospores. In nature, barley seed come into contact with wind-dispersed teliospores or teliospores from infested neighboring seed. Teliospores overwinter under the seed hull and then germinate with the seed in the spring to form a promycelium. Under favorable conditions, two basidiospores of opposite mating type fuse and form a dikaryotic mycelium, which needs the host for survival and to complete its life cycle (Hu et al. 2002). After penetrating the plant cuticle through an appressorium-like structure, the fungus enters its biotrophic phase, eluding and suppressing host defenses. Hyphae colonize intercellular spaces and transverse cell layers to reach the shoot meristem, where it establishes itself quiescently until differentiation of this meristem to floral tissue takes place. In the spikelets of the inflorescence, the fungus proliferates and, upon emergence, barley kernels have been replaced with masses of black sooty teliospores $(\mathrm{Hu}$ et al. 2002).

In this study, we present the analysis of U. hordei Cnal and $\mathrm{Cnbl}$ deletion mutants. Aspects of the effects of environmental stresses, including the host environment of similar mutations in a variety of fungi, have been reported individually in different publications. We carried out a comprehensive study in this pathosystem and revealed that the $U$. hordei mutants were sensitive to agents that impose stress in the endoplasmic reticulum (ER) and showed severe defects in cell-wall construction; intact cell walls or the capability to modify them upon host infection are important for fungal virulence (Arbelet et al. 2010; Joubert et al. 2010; Klippel et al. 2010; Treitschke et al. 2010). We also identified novel response genes. Through the calcineurin pathway, $U$. hordei orchestrates proper responses to several types of environmental stress such as variation in the $\mathrm{pH}$, salinity, and presence of heavy metals in the culture media, as well as temperature, oxidative, acid, nitrosative, and genotoxic stresses. As a result, $\Delta c n a l$ and $\Delta c n b 1$ deletion mutants are also severely affected in virulence toward barley plants.

\section{RESULTS}

\section{Identification and cloning of $\boldsymbol{U}$. hordei calcineurin genes.}

$U$. hordei genes encoding the calcineurin catalytic (UhCnal) and regulatory $(U h C n b l)$ subunits were identified by in silico searches of the $U$. hordei genome database at the Munich Information Center for Protein Sequences MIPS (R. Kahmann, J. Schirawski, and G. Bakkeren, unpublished). Using the blastx algorithm (Altschul et al. 1997), this database was searched with previously reported fungal calcineurin proteins as queries. To obtain UhCnal, we used Cnal protein sequences from $U$. maydis (AAP48999), C. neoformans (XP_567518), A. fumigatus (XP_753703), Candida albicans (XM_713902), B. cinerea (XP_001558972), S. sclerotiorum (XP_001597594), and M. grisea (XP_367545); and, to retrieve $\bar{U} h C n b 1$, we used Cnb1-homologous sequences from Cryptococcus neoformans (XP_775641), U. maydis (EAK82139), B. cinerea (ABN54442), Saccharomyces cerevisiae (NP_012731), and Sclerotinia sclerotiorum (XP_001598128). Putative homologous genes UH_01405 (catalytic subunit) and UH_01914 (regulatory subunit; Supplementary Table S1) were selected according to the highest score obtained. Both genes appeared intron-less and encoded the predicted proteins UhCnal (629 amino acids) and UhCnb1 (176 amino acids). The closest homologs were found in other basidiomycetes: for UhCnal, in U. maydis, Malazzesia globosa, C. neoformans, and Coprinopsis cinerea, with 95, 76, 74 , and $71 \%$ amino acid identity, respectively; and, for UhCnb1, in U. maydis, Postia placenta, and Cryptococcus neoformans, sharing 97, 80, and $78 \%$ amino acid identity, respectively. UhCnb1 appeared to have two calcium-binding motifs (EFh), and the well-conserved phosphatase catalytic domain (PP2Ac), a signature in proteins belonging to the serine-threonine phosphatase family, was present at the amino terminus of UhCna1. Genes with estimated promoter and terminator elements on either side of the presumed start and stop codons, respectively, were amplified by polymerase chain reaction (PCR) and cloned into either episomal or integrative plasmids for genetic complementation of generated mutants.

\section{Deletion of UhCnal and $U$ hCnb1 genes.}

$U$. hordei protoplasts from wild-type strains Uh364 (MAT-1) or Uh365 (MAT-2) (Table 1) were each transformed with plasmids 1,178 or 1,176 to delete the UhCnal and $U h C n b 1$ genes, respectively, by marker-exchange (discussed below). Proper gene deletion was confirmed by DNA blot (Supplementary Fig. S1) and the following set of mutants was selected to conduct further experiments: Uh1011 and Uh1013 (Acnal, MAT1), Uh1015 and Uh1016 ( $\triangle$ cnal, MAT-2), Uh1123 and Uh1176 $(\Delta c n b 1, M A T-1)$, and Uh976 and Uh978 ( $\Delta c n b 1, M A T-2)$, collectively referred to as calcineurin mutants. The recovery of deletion mutants of either gene in haploid strains indicated that these genes are not essential in $U$. hordei when grown under normal culture conditions.

\section{Phenotypic analysis of calcineurin mutants.}

Morphological changes caused by impaired function of calcineurin. In standard growing media such as complete medium (CM), yeast extract-peptone-sucrose (YEPS) or potato dextrose broth (PDB), calcineurin mutants showed altered cell morphology. Cells looked hyperbranched and a clear tendency to form small microscopic aggregates was observed, in contrast to the parental strains, Uh364 or Uh365, which, under similar growing conditions, grew normally as a uniform population of yeast-like cells (Fig. 1). Similar cell morphological changes were observed in ucnl (calcineurin catalytic subunit) mutants of $U$. maydis, which also resulted in a wrinkled colony morphology (Egan et al. 2009), similar to that found for Candida albicans cnal homozygous mutants (Sanglard et al. 2003). In contrast, the colony morphology of the $U$. hordei calcineurin mutants was not altered, and creamy-looking colonies of similar shape and size were observed for both wild-type and mutant strains (data not shown). Cell morphology was also reported to be affected in A. fumigatus $\triangle c n a A$ strains (Steinbach et al. 2006).

Calcineurin pathway is involved in cell-wall integrity. Wildtype, $\Delta c n a l$ and $\Delta c n b l$ strains were grown on CM supplemented with compounds known to reveal cell-wall defects. Mutants were not viable when either $0.002 \%$ sodium dodecyl sulfate (SDS), Congo red (CR) at $8.5 \mu \mathrm{g} \mathrm{ml}^{-1}$, Calcofluor white $(\mathrm{CFW})$ at $20 \mu \mathrm{g} \mathrm{ml}^{-1}$, or $0.09 \mathrm{mM}$ caffeine were present in the culture media (Fig. 2), although caffeine seemed to be the least harmful agent. Similar responses to all compounds were observed for both mutants. A cumulative effect was observed with SDS plus CR, because mutants were not able to grow when lower concentrations of both compounds were added to- 
gether in the medium $\left(0.0003 \%\right.$ SDS and $\mathrm{CR}$ at $4 \mu \mathrm{g} \mathrm{ml}^{-1}$; data not shown). The effect of high osmotic medium when supplemented with $1.2 \mathrm{M}$ sorbitol or mannitol was tested but found to not affect growth because both wild-type and mutant colonies grew at the same extent (data not shown). The effect of the above compounds was also tested in the presence of $1 \mathrm{M}$ sorbitol but no improvement in growth was observed for the calcineurin mutants (data not shown). Overall, these experiments suggested that cell-wall defects might be present. This was further substantiated by the reduced number of CFU recovered after partial cell-wall digestion with lysing enzymes from Trichoderma harzianum and subsequent incubation on CM without osmotic support such as $1 \mathrm{M}$ sorbitol normally used for protoplast regeneration. For example, in a comparative test, $1.41 \pm 0.19 \times 10^{6} \mathrm{CFU}$ were recovered from the Uh365 wildtype strain, whereas only $1.4 \pm 0.35 \times 10^{4}$ and $2 \pm 0.28 \times 10^{4}$ $\mathrm{CFU}$ were obtained from $\Delta c n a l$ and $\Delta c n b l$ mutants, respec-
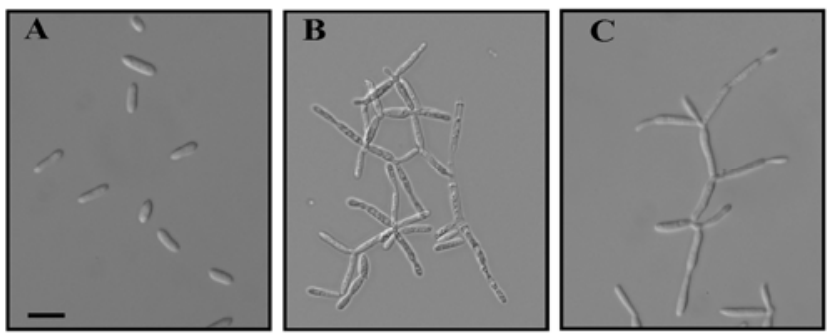

Fig. 1. In vitro cell morphology is altered due to deletion of UhCnal or UhCnbl genes. The indicated strains were grown in liquid complete medium at $22^{\circ} \mathrm{C}$ in constant shaking. Samples were withdrawn after $36 \mathrm{~h}$ and cells were observed with a Zeiss Axiophot microscope using DIC optics. Scale bar is $5 \mu \mathrm{m}$. A, Uh365 wild-type strain; B, $\Delta c n a 1$ (Uh1015); and C, $\Delta c n b 1$ (Uh978). tively. Data represent an average of three experiments with triplicate samples each.

Finally, sensitivity to Fludioxonil was assayed. Addition of this fungicide to the medium results in cell lysis due to an increase of internal glycerol through the activation of the Hog1 pathway (Kojima et al. 2006). The effect of this compound
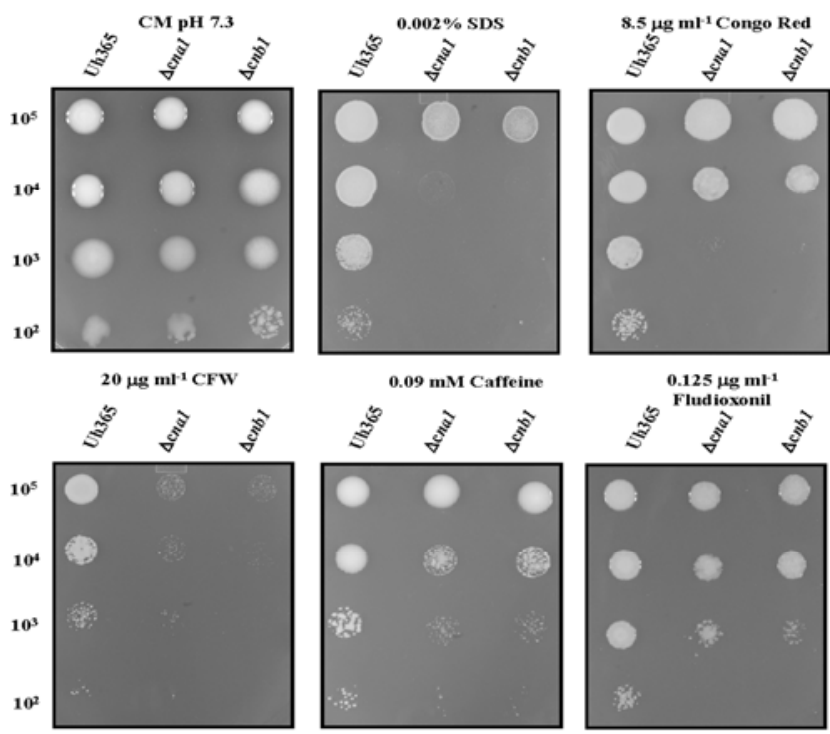

Fig. 2. Cell-wall-perturbing agents are harmful to $\Delta c n a l$ and $\Delta c n b 1 \mathrm{mu}-$ tants. Strains were grown in liquid complete medium $(\mathrm{CM})$ at $22^{\circ} \mathrm{C}$ for 36 h. Optical density at $600 \mathrm{~nm}$ of the cultures was adjusted to $0.8 ; 10 \mu \mathrm{l}$ of 10 -fold serial dilutions were spotted on $\mathrm{CM}$ adjusted to $\mathrm{pH} 7.3$ as control condition. Similar media were amended with the compounds indicated. Plates were incubated at $22^{\circ} \mathrm{C}$ for 5 days, after which they were photographed. Uh365, wild-type strain; $\Delta c n a 1$ (Uh1015); $\Delta c n b 1$ (Uh978).

Table 1. Strains used in this work ${ }^{\mathrm{a}}$

\begin{tabular}{|c|c|c|}
\hline Strain ID & Relevant genotype & Source \\
\hline Uh364 & $M A T-1$ & Wild type; Lining et al. 2004 \\
\hline Uh365 & $M A T-2$ & Wild type; Lining et al. 2004 \\
\hline \multicolumn{3}{|c|}{ Deletion strains } \\
\hline Uh1011 & $M A T-1, \Delta c n a l \mathrm{cbx}^{\mathrm{r}}$ & This work \\
\hline Uh1013 & $M A T-1, \Delta c n a l \mathrm{cbx}^{\mathrm{r}}$ & This work \\
\hline Uh1015 & $M A T-2, \Delta c n a l \mathrm{cbx}^{\mathrm{r}}$ & This work \\
\hline Uh1016 & $M A T-2, \Delta c n a l \mathrm{cbx}^{\mathrm{r}}$ & This work \\
\hline Uh1123 & $M A T-1, \Delta c n b 1 \mathrm{cbx}^{\mathrm{r}}$ & This work \\
\hline Uh1176 & $M A T-1, \Delta c n b 1 \mathrm{cbx}^{\mathrm{r}}$ & This work \\
\hline Uh976 & $M A T-2, \Delta c n b 1 \mathrm{cbx}^{\mathrm{r}}$ & This work \\
\hline Uh978 & $M A T-2, \Delta c n b 1 \mathrm{cbx}^{\mathrm{r}}$ & This work \\
\hline \multicolumn{3}{|c|}{ Complemented strains $\left(\Delta c n a l ; \mathrm{cbx}^{\mathrm{r}}\right)$} \\
\hline Uh1094 & Uh1015 plus $1223^{\text {ep }}$ UhCnal, hyg ${ }^{\mathrm{r}}$ & This work \\
\hline Uh1095 & Uh1015 plus $1223^{\text {ep }}$ UhCnal, hyg ${ }^{\mathrm{r}}$ & This work \\
\hline Uh1096 & Uh1015 plus $1220^{\mathrm{ep}}$ Ucn 1 , hyg ${ }^{\mathrm{r}}$ & This work \\
\hline Uh1097 & Uh1015 plus $1220^{\text {ep }}$ Ucnl, hyg $^{\mathrm{r}}$ & This work \\
\hline Uh1099 & Uh1011 plus $1223^{\text {ep }}$ UhCnal, hyg ${ }^{\mathrm{r}}$ & This work \\
\hline Uh1100 & Uh1011 plus $1223^{\text {ep }}$ UhCnal, hyg ${ }^{\mathrm{r}}$ & This work \\
\hline Uh1102 & Uh1011 plus $1220^{\mathrm{ep}}$ Ucn1, hyg ${ }^{\mathrm{r}}$ & This work \\
\hline Uh1103 & Uh1011 plus $1220^{\text {ep }} U c n 1$, hyg $^{\mathrm{r}}$ & This work \\
\hline Uh1216 & Uh1015 plus $1223^{\text {int }}$ UhCnal, hyg ${ }^{\mathrm{r}}$ & This work \\
\hline Uh1217 & Uh1015 plus $1223^{\text {int }}$ UhCnal, hyg ${ }^{\mathrm{r}}$ & This work \\
\hline Uh1219 & Uh1011 plus $1223^{\text {int }}$ UhCnal, hyg ${ }^{\mathrm{r}}$ & This work \\
\hline Uh1220 & Uh1011 plus $1223^{\text {int }}$ UhCnal, hyg ${ }^{\mathrm{r}}$ & This work \\
\hline \multicolumn{3}{|c|}{ Complemented strains $\left(\Delta c n b 1 ; \mathrm{cbx}^{\mathrm{r}}\right)$} \\
\hline Uh1080 & Uh978 plus $1219^{\mathrm{ep}} \mathrm{UmCnb1}$, hyg ${ }^{\mathrm{r}}$ & This work \\
\hline Uh1081 & Uh978 plus $1219^{\mathrm{ep}} \mathrm{UmCnb1}$, hyg ${ }^{\mathrm{r}}$ & This work \\
\hline Uh1105 & Uh978 plus $1222^{\text {int }} U h C n b 1$, zeo $^{\mathrm{r}}$ & This work \\
\hline Uh1106 & Uh978 plus $1222^{\text {int }}$ UhCnb1, zeo ${ }^{\mathrm{r}}$ & This work \\
\hline Uh1262 & Uh1123 plus $1222^{\text {int }}$ UhCnb1, zeo ${ }^{\mathrm{r}}$ & This work \\
\hline Uh1263 & Uh1123 plus $1222^{\text {int }} U h C n b 1$, zeo $^{\text {r }}$ & This work \\
\hline
\end{tabular}

a All mutants were generated in the Uh364 or Uh365 genetic background as indicated. Superscripts: $r=$ resistant to the indicated antibiotic, ep = episomal complementing plasmid, and int = integrative complementing plasmid. 
will be exacerbated in strains with fragile cell walls. The wildtype strains, Uh364 or Uh365, were sensitive to fludioxonil at concentrations as low as $2.5 \mu \mathrm{g} \mathrm{ml}^{-1}$. However, the calcineurin mutants $\Delta c n a l$ or $\Delta c n b l$ were more sensitive to this fungicide, with growth inhibited by the addition of just $0.125 \mu \mathrm{g} \mathrm{ml}^{-1}$ (Fig. 2). This result is in agreement with the sensitivity observed in a Cryptococcus neoformans $\Delta$ cnal mutant (Fan et al. 2007). Fludioxonil is prepared in dimethyl sulfoxide (DMSO) but no detrimental effect was observed by the addition of DMSO alone (data not shown).

Synthesis of 1,3- $\beta$-D-glucan is increased in calcineurin mutants under salt stress. Proper cell-wall construction is directly related to the synthesis and assembly of $1,3-\beta-D$-glucan (Lesage and Bussey 2006). This fact prompted us to determine whether the compromised cell-wall integrity exhibited by $\Delta c n a l$ and $\Delta c n b l$ mutants could be related to the total amount of this polysaccharide. Both wild-type cells and mutants revealed similar amounts of 1,3- $\beta$-D-glucan when grown under standard conditions (Uh365: $0.24 \pm 0.027 \mu \mathrm{g} \mathrm{mg} \mathrm{wt}^{-1} ; \Delta c n a l$ : $\left.0.26 \pm 0.006 \mu \mathrm{g} \mathrm{mg} \mathrm{wt}{ }^{-1} ; \Delta c n b 1: 0.26 \pm 0.027 \mu \mathrm{g} \mathrm{mg} \mathrm{wt}^{-1}\right)$. This result contrasts with the reduction of 1,3- $\beta$-D-glucan content observed in wild-type $S$. sclerotiorum cells grown in PDB media amended with CsA, which mimics calcineurin mutants by strongly inhibiting calcineurin phosphatase (Harel et al. 2006), or in A. fumigatus $\triangle$ cnaA cells grown in RPMI medium (Cramer et al. 2008). On the other hand, when a stress was imposed to the cells $(\mathrm{CM}, \mathrm{pH} 7.3$, amended with $500 \mathrm{mM} \mathrm{NaCl}$ for $30 \mathrm{~min}$ ), the amount of 1,3- $\beta$-D-glucan increased 1.6-fold in the wild-type Uh365 strain but more than fivefold in the calcineurin mutants $\left(\Delta c n a l: 1.3 \pm 0.09 \mu \mathrm{g} \mathrm{mg} \mathrm{wt}^{-1}\right.$ and $\Delta c n b 1$ : $\left.1.5 \pm 0.08 \mu \mathrm{g} \mathrm{mg} \mathrm{wt}^{-1}\right)$. This effect was exacerbated when cells were subjected to a less severe saline stress but for longer (CM, pH 7.3, amended with $250 \mathrm{mM} \mathrm{NaCl}$ for $4 \mathrm{~h}$ ), resulting in 10- to 12 -fold higher $1,3-\beta$-D-glucan content in the calcineurin mutants $\left(\Delta c n a l: 2.6 \pm 0.07 \mu \mathrm{g} \mathrm{mg} \mathrm{wt}^{-1}\right.$ and $\Delta c n b 1$ : $2.7 \pm 0.09 \mu \mathrm{g} \mathrm{mg} \mathrm{wt}^{-1}$ ) compared with wild-type strain Uh365 $\left(0.22 \pm 0.16 \mu \mathrm{g} \mathrm{mg} \mathrm{wt}^{-1}\right)$.

The finding that the 1,3- $\beta$-D-glucan content in the calcineurin mutants was more then 10-times higher when grown under moderate saline stress (CM, pH7.3, and $250 \mathrm{mM} \mathrm{NaCl}$ for 4 $\mathrm{h}$ ), prompted us to determine whether this had any bearing on their cell wall or would change their sensitivity to the effects
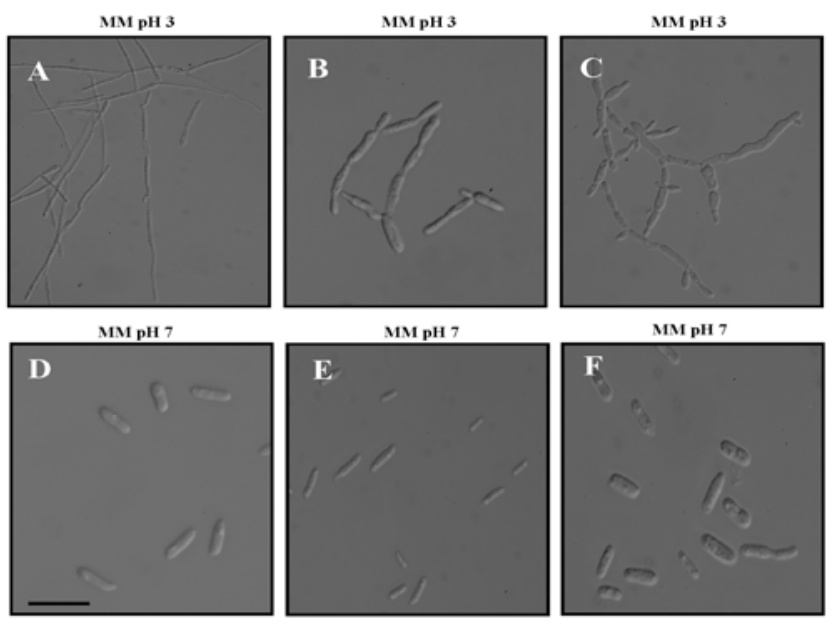

Fig. 3. Effect of UhCnal and UhCnbl deletion on cell-morphological transition under acidic conditions. The indicated strains were grown in liquid complete medium at $22^{\circ} \mathrm{C}$ for $36 \mathrm{~h}$. Cells were inoculated in liquid minimal medium with $\mathrm{pH}$ as indicated and samples were observed after 32 $\mathrm{h}$ with a Zeiss Axiophot microscope using DIC optics. A and D, Uh365 wild-type strain; B and E, $\Delta c n a l$ (Uh1015); and $\mathbf{C}$ and F, $\Delta c n b 1$ (Uh978). Scale bar: $10 \mu \mathrm{m}$. of T. harzianum lysing enzymes. However, $\Delta c n a l$ and $\Delta c n b l$ mutant cells grown under these moderate saline stress conditions were still more sensitive than wild-type Uh365 cells to cell-wall digestion treatment, according to the number of CFU recovered (data not shown). Even though higher amounts of glucan are present in the calcineurin mutants, its distribution or incorporation in the cell wall might be compromised or an impaired calcineurin pathway might affect the proportion or distribution of other important cell-wall components such as chitin or chitosan, thereby maintaining their increased sensitivity to the lysing enzymes. All specificities of the various cellwall-degrading activities in the complex lysing enzyme cocktail are not known.

Sensitivity to $\mathrm{pH}$ and peptone. $U$. hordei wild-type strains displayed hyphal growth when cultured under acidic conditions. After transfer of $U$. hordei Uh364 or Uh365 wild-type cells from $\mathrm{CM}$ to liquid minimal medium (MM) at $\mathrm{pH} 3$, elongated hyphal cells were observed. In contrast, a uniform population of yeast-like cells is maintained in $\mathrm{MM}$ at neutral $\mathrm{pH}$ (Fig. 3, compare panels A and D). Interestingly, the change in cell morphology of the calcineurin mutants cultured under the same conditions was different: cells were still elongated in acidic medium but shorter and thicker hyphae with some visible constrictions were observed (Fig 3, compare panels B and $\mathrm{C}$ to A). Additionally, $\Delta c n b 1$ cells seemed to produce branched hyphae (Fig. 3, panel C). On the other hand, at neutral $\mathrm{pH}$ (MM, pH 7), the mutants grew as budding yeast, as was seen for the wild-type cells, although $\Delta$ cnal cells were slightly more elongated than the wild-type or $\Delta c n b 1$ cells.

We have observed that $U$. hordei strains are sensitive to small changes in the $\mathrm{pH}$ of the culture media. Essentially, values from neutral to a mildly alkaline $\mathrm{pH}$ resulted in an increasing detrimental effect on growth. Uh364 or Uh365 wild-type strains were not able to grow on $\mathrm{CM}$ adjusted to $\mathrm{pH}$ higher than 8.3 (data not shown). The calcineurin mutants ( $\Delta$ cnal or $\Delta c n b 1)$ were affected much more strongly by $\mathrm{pH}$ because they grew poorly on $\mathrm{CM}$ adjusted to $\mathrm{pH} 7.6$, whereas no growth was observed when the $\mathrm{pH}$ was raised to 7.8 (Supplementary Fig. S2).

For an unknown reason, $\Delta c n a l$ or $\Delta c n b l$ mutants were not able to properly grow when peptone was present in media (such as in YEPS). This effect was also reported for the $U$. maydis $\Delta u c n 1$ mutant (Egan et al. 2009). In contrast, $U$. hordei mutants $(\Delta c n a l$ or $\Delta c n b 1)$ grew at the same rate as the wildtype strain in $\mathrm{CM}$, which does not contain peptone (data not shown).

$\Delta c n a l$ and $\Delta c n b 1$ mutants are not resistant to a calcineurin inhibitor. In the human pathogens $C$. neoformans or A. fumigatus, mutation of the CsA target site or deletion of the calcineurin A gene renders these mutants resistant to inhibitors of this pathway such as CsA or FK506 (Cruz et al. 2001; da Silva Ferreira et al. 2007). We tested how the $U$. hordei calcineurin mutants responded to the presence of CsA in the culture media. Wild-type strains Uh364 or Uh365 were sensitive to this compound, because a growth inhibitory halo was formed after 4 days of incubation $(2.0 \pm 0.1 \mathrm{~cm} ; n=3)$. In contrast to the findings for the human fungal pathogens, the U. hordei $\Delta c n a l$ and $\Delta c n b 1$ mutants were sensitive to this compound as well, because growth inhibitory halos of similar sizes were formed by $\Delta$ cnal $(2.2 \pm 0.2 \mathrm{~cm} ; n=3)$ or by $\Delta c n b l(2.0 \pm 0.2 \mathrm{~cm} ; n=$ $3)$ cells. No significant inhibition was observed when the CsA solvent ethanol was tested alone (data not shown). This suggests that CsA has additional targets in $U$. hordei cells whose inhibition affects growth.

Sensitivity to monovalent and divalent cations. The presence in the media of mono or divalent cations was toxic to calcineurin mutants. A dramatic inhibition in their growth was 
observed on CM (pH 7.3) plates supplemented with the following cations separately at different concentrations: $30 \mathrm{mM}$ $\mathrm{CsCl}, 40 \mathrm{mM} \mathrm{LiCl}, 600 \mathrm{mM} \mathrm{NaCl}, 30 \mathrm{mM} \mathrm{MnCl} 2,20 \mathrm{mM}$ $\mathrm{MgCl}_{2}$, or $600 \mathrm{mM} \mathrm{CaCl}$. Regarding the monovalent cations, the most dramatic effect was observed with $\mathrm{Cs}^{+}$, because both mutants did not grow at all in its presence. Both mutants behaved similarly in the presence of $\mathrm{Li}^{+}$but, curiously, $\Delta$ cnal was more sensitive to the effect of $\mathrm{Na}^{+}$than $\Delta c n b 1$ (Fig. 4; Supplementary Fig. S3). With respect to divalent cations, calcineurin mutants showed similar responses to $\mathrm{Mn}^{2+}$ and $\mathrm{Mg}^{2+}$ but seemed more sensitive to $\mathrm{Ca}^{2+}$; for both wild-type strain and mutants, growth was delayed in the presence of this cation given that plates were incubated for 9 days (Fig. 4).

The result that high levels of calcium inhibited the growth of calcineurin mutants suggested that they might not be able to respond as efficiently to $\mathrm{Ca}$-ion fluctuations in the environment. Therefore, we also evaluated the response of these strains to depletion of calcium ions by adding the calcium chelating agent EGTA to the growing media. Low concentrations of this compound $(1 \mathrm{mM})$ were sufficient to completely inhibit the growth of the $\Delta c n b l$ mutant and a drastic reduction in growth was observed for the $\Delta c n a l$ mutant, whereas EGTA addition had almost no effect on a wild-type strain (Fig. 4). These data suggest that the calcineurin pathway is very important in sensing or responding to fluctuations in environmental calcium levels, given that either high concentration or calcium depletion in the medium drastically compromised viability. To corroborate this further, we tested the response of the calcineurin mutants to the effect of the calcium ionophore, A23187, which increases intracellular $\mathrm{Ca}^{2+}$ levels. In Claviceps purpurea, a calcium channel 1 (Midl) deletion mutant was unable to grow in the presence of this compound whereas the wild-type strain was unaffected (Bormann and Tudzynski 2009). However, in $U$. hordei, we found that both the wild-type strain and the calcineurin mutants were equally sensitive to the presence of A23187, because a similar growth inhibition was observed (data not shown). The inhibitory growth effect of the ionophore and presumed increase in internal $\mathrm{Ca}^{2+}$ levels could mimic the overall slower growth we observed in the medium with high $\mathrm{Ca}^{2+}$ levels (Fig. 4).

Enhanced sensitivity of calcineurin mutants to chemical ER stress. Intracellular calcium levels are maintained by the action of $\mathrm{Ca}^{2+}$ pumps located in membranes of vacuoles, Golgi apparatus, and ER. The ER is the main dynamic calcium storage compartment, where a physiological threshold of calcium is required for the proper folding and secretion of proteins (Meldolesi and Pozzan 1998). Bonilla and associates (2002) described the calcium cell survival (CCS) pathway in Saccharomyces cerevisiae as a protective mechanism whose activation is triggered in cells undergoing ER stress. Calcium influx is conducted through the Cch1p-Mid1p channel, which subsequently activates the calcineurin pathway, thereby improving cell survival (Bonilla and Cunningham 2003; Bonilla et al. 2002). Therefore, we measured the behavior of the calcineurin mutants upon treatment with chemical agents that impose ER stress. We assayed the effect of tunicamycin (Tm), which blocks the synthesis of $\mathrm{N}$-linked glycoproteins in the ER (Kukuruzinska and Lennon 1995), and dithiothreitol (DTT), which disrupts formation of disulfide bonds and leads to retention of proteins in the ER (Jamsa et al. 1994). U. hordei calcineurin mutants were unable to manage the ER stress imposed by these chemicals, because we observed that both, $\Delta$ cnal and $\Delta c n b 1$ mutants barely grew in the presence of $\mathrm{Tm}(0.1 \mu \mathrm{M})$ and were severely impaired by the effect of $50 \mu \mathrm{M}$ DTT, whereas no significant growth reduction was seen for the wildtype strains in the presence of these agents (Fig. 4). Interestingly, the $\Delta c n a l$ mutant was more resistant to the effect of
DTT than the $\Delta c n b 1$ mutant (Fig. 4). This data is in agreement with the phenomenon observed in S. cerevisiae, where cell death under ER stress is prevented via signaling through the calcineurin pathway (Bonilla and Cunningham 2003; Bonilla et al. 2002).

Deleterious effect of physical and chemical challenges. Both $\Delta c n a l$ and $\Delta c n b 1$ calcineurin mutants were not able to tolerate a constant incubation temperature of $28^{\circ} \mathrm{C}\left(6^{\circ} \mathrm{C}\right.$ above optimal of $22^{\circ} \mathrm{C}$ ) (Fig. 5). They were not able to recover after a heat shock treatment at $39^{\circ} \mathrm{C}$ for 40 min was applied; in contrast, wild-type strains were not affected by such treatment (Fig. 5). The calcineurin mutants $\Delta c n a l$ or $\Delta c n b l$ seemed equally sensitive to the harmful effect of UV light (Fig. 5), suggesting inability of mutants to properly respond to genotoxic agents such as UV-generated oxygen radicals (and subsequent DNA damage). In the same way, these mutants were sensitive to ZeocinTM, another genotoxic agent. A low concentration of this compound (10 $\mathrm{ng} \mathrm{ml}^{-1}$ ) was enough to inhibit the growth of $\Delta c n a l$ and $\Delta c n b l$ cells, in contrast to the wild-type strain, whose growth was not inhibited by this low concentration of ZeocinTM (data not shown). Exposure of the $\Delta c n a l$ and $\Delta c n b 1$ mutants to oxidative or acid stresses imposed by $\mathrm{H}_{2} \mathrm{O}_{2}$ (17.4 $\mathrm{mM}$ for $90 \mathrm{~min}$ ) or acetic acid $(161 \mathrm{mM}$ for $25 \mathrm{~min}$ ), respectively, resulted in a great reduction in their growth, especially when treated with acetic acid (Fig. 5). Interestingly, the $\Delta$ cnal mutants were more sensitive to oxidative stress but more resistant to acid stress than the $\Delta c n b 1$ mutants. Because the calcineurin mutants were considerably damaged by oxidative stress generated by $\mathrm{H}_{2} \mathrm{O}_{2}$, we also tested their response to singlet oxygen $\left({ }^{1} \mathrm{O}_{2}\right)$, another very harmful reactive oxygen species which can be produced by the addition to the medium of the dye Rose Bengal (RB) (Brombacher et al. 2006). Both $\Delta c n a l$ and $\Delta c n b 1$ mutants were severely affected by this compound, given that they barely grew on $\mathrm{CM}(\mathrm{pH} 7.3)$ plates amended with $100 \mu \mathrm{M}$ RB (Fig. 5). Calcineurin mutants were also incapable of overcoming the nitrosative stress damage produced by the addition of $\mathrm{NaNO}_{2}(20 \mathrm{mM})$, whereas this detrimental effect was not observed in wild-type strains (data not shown).

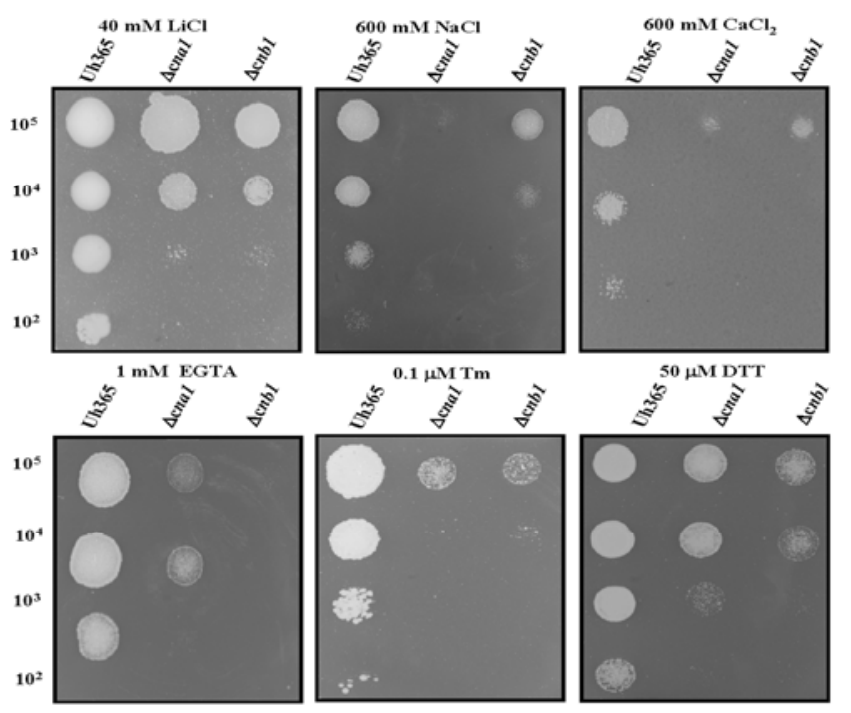

Fig. 4. Calcineurin is important for protection against cations and chemical endoplasmic reticulum stress. Strains were grown in liquid complete medium (CM) at $22^{\circ} \mathrm{C}$ for $36 \mathrm{~h}$. Optical density at $600 \mathrm{~nm}$ of the cultures was adjusted to 0.8 and aliquots of $10 \mu \mathrm{l}$ were spotted onto $\mathrm{CM}(\mathrm{pH} \mathrm{7.3)}$ amended with the amount of the compound indicated in each panel. Plates were incubated at $22^{\circ} \mathrm{C}$ and photographed after 4 days, except plates with $\mathrm{NaCl}$ or $\mathrm{CaCl}_{2}$, which were incubated for 9 days, respectively. Uh365, wild-type strain; $\Delta c n a l$ (Uh1015); $\Delta c n b 1$ (Uh978). 
Effect of heavy metals. $U$. hordei calcineurin mutants were not able to tolerate very well the presence of heavy metals in the culture media. Compared with wild-type cells, we observed severe growth reduction at the same degree in both $\Delta c n a l$ and $\Delta c n b 1$ mutants in the presence of $10 \mathrm{mM} \mathrm{Zn}^{2+}, 1 \mathrm{mM} \mathrm{Cu}^{2+}, 15$ $\mathrm{mM} \mathrm{Fe}{ }^{3+}, 1 \mathrm{mM} \mathrm{Cr}^{6+}, 0.5 \mathrm{mM} \mathrm{Co}{ }^{2+}$ or, to a lesser extent, $1 \mathrm{mM}$ $\mathrm{Ni}^{+}$, respectively (Supplementary Fig. S4; data not shown). Curiously, $\Delta c n b l$ was more sensitive than $\Delta c n a l$ to $1 \mathrm{mM}$ $\mathrm{Cu}^{2+}$ but was more resistant to the effect of $1 \mathrm{mM} \mathrm{CrO}_{3}$.

Mating is not impaired but delayed in calcineurin mutants. Before infecting a host plant, all smut species require successful mating between compatible haploid cells to form the dikaryotic infection hyphae (Bakkeren et al. 2006). We investigated whether the ability to mate was affected in the $U$. hordei calcineurin mutants. On solid MM pH 7 medium, a compatible wild-type cross of strains Uh364 (MAT-1) $\times$ Uh365 (MAT-2) produced a positive mating reaction after $24 \mathrm{~h}$, typified by short, meandering mating hyphae and long, septated infection hyphae after fusion (Fig. 6A and C). Similar structures were observed in a compatible $\Delta c n a l$ cross, $($ Uh1011 $\times$ Uh1015) but only after $48 \mathrm{~h}$ incubation (Fig. 6B and D); comparable results were obtained for a compatible $\Delta c n b 1$ cross (Uh1123 $\times$ Uh978) (data not shown). Under our assay conditions, similar fractions of cells produced the mating interactions in both wild-type and mutant cells. Our findings show that the $U$. hor-

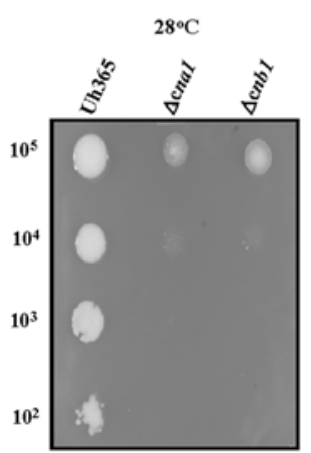

$17.4 \mathrm{mM} \mathrm{H}_{2} \mathrm{O}_{2}$

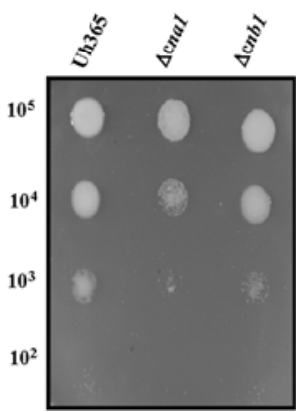

Fig. 5. Deletion of calcineurin-encoding genes render mutants susceptible to several stresses. The indicated strains were grown in liquid complete medium $(\mathrm{CM})$ at $22^{\circ} \mathrm{C}$ for $36 \mathrm{~h}$. Optical density at $600 \mathrm{~nm}\left(\mathrm{OD}_{600}\right)$ of the cultures was adjusted to 0.8 . Then, $10-\mu$ laliquots were spotted on $\mathrm{CM}(\mathrm{pH}$ 7.3). For suboptimal incubation temperature, one plate was incubated at $28^{\circ} \mathrm{C}$. For heat shock, $1 \mathrm{ml}$ of cells $\left(\mathrm{OD}_{600}\right.$ of 0.8$)$ was heated at $39^{\circ} \mathrm{C}$ for $40 \mathrm{~min}$, diluted, and spotted as above onto $\mathrm{CM}$ (pH 7.3). For UV light treatment, cells were spotted as above onto $\mathrm{CM}(\mathrm{pH} 7.3)$ and plates allowed to dry, whereafter UV light was applied. For oxidative or acid stresses, $1 \mathrm{ml}$ of cells $\left(\mathrm{OD}_{600}\right.$ of 0.8$)$ was treated with $\mathrm{H}_{2} \mathrm{O}_{2}(17.4 \mathrm{mM})$ for $25 \mathrm{~min}$ or with acetic acid $(161 \mathrm{mM})$ for 90 min with shaking at $22^{\circ} \mathrm{C}$. Next, cells were diluted as above and $10 \mu \mathrm{l}$-aliquots were spotted on $\mathrm{CM}$ ( $\mathrm{pH}$ 7.3). For the Rose Bengal treatment, cells were diluted and spotted as above on plates amended with the compound. Plates were photographed after 4 days of incubation at $22^{\circ} \mathrm{C}$, except for the suboptimal temperature experiment which was incubated at $28^{\circ} \mathrm{C}$ during the same time. Uh365, wild-type strain; $\Delta c n a l$ (Uh1015); $\Delta c n b 1$ (Uh978). dei calcineurin mutants are still able to sense and respond to pheromone but produce a delayed morphological response, possibly due to a less effective cell-wall remodeling. For $U$. maydis ucnl (calcineurin catalytic subunit) mutants, a drastic reduction in mating was reported (Egan et al. 2009); however, this was assayed as a "fuzzy" colony phenotype on conventional charcoal-containing CM plates, which represents a less sensitive assay than microscopic observation of cell interactions.

Virulence is impaired in calcineurin mutants. The calcineurin pathway has been shown to be involved in virulence in both plant and human fungal pathogens (Bader et al. 2003; Cramer et al. 2008; Choi et al. 2009; Fox et al. 2001). Mating did not seem to be (grossly) impaired; therefore, we investigated whether $U$. hordei calcineurin mutants were affected in their virulence toward barley plants. Barley seed were inoculated with mixtures of sexually compatible crosses MAT-1 $\times M A T-2$ (mutant $\times$ mutant or wild-type $\times$ mutant; two sets of mutants were tested) and plants were scored for disease symptoms upon heading. Indeed, disabling the calcineurin pathway affected virulence, given that drastically reduced numbers of infected plants with smutted heads were obtained when inoculated with compatible mixtures in which both mating partners had the mutant genotype $\Delta c n a l$ or $\Delta c n b 1$ (Fig. 7 , representative data). In contrast, over $60 \%$ of diseased plants were obtained from seed inoculated with the wild-type cross Uh364 $\times$ Uh365 (Fig. 7). Importantly, when seed were inoculated with a cross of $\triangle$ cnal $(M A T-1) \times \Delta c n b l$ (MAT-2), an intermediate level of disease was obtained in which $44 \%$ of inoculated plants developed smutted heads; this result indicates the recessive nature of each mutation, which can be compensated for by a single wild-type allele in one of each partner in the mated dikaryon (Fig. 7). It is unclear why, in those crosses, full virulence is not restored; there could be a gene-dosage effect because each wild-type allele resides in a separate nucleus in the dikaryotic infection hyphae, or effects on early mating interactions between single mutant haploid partners, as described above, might delay infection. Virulence was regained to a comparable wild-type level when deletion mutants were complemented with the respective $U$. hordei wild-type UhCnal
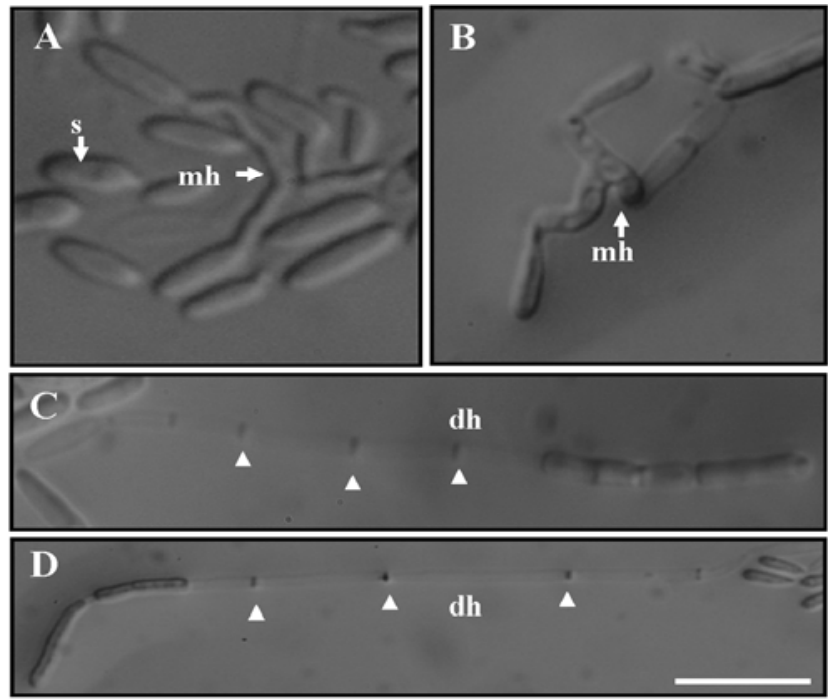

Fig. 6. Mating is delayed but not abolished in calcineurin mutants. Strains were grown in liquid complete medium for $24 \mathrm{~h}$, after which cells of compatible mating type were diluted, mixed, and spread on a thin layer of minimal medium ( $\mathrm{pH} 7$ ) agar applied on a microscope slide. DIC images were taken after microscope slides were incubated at $22^{\circ} \mathrm{C}$ for $\mathbf{A}$ and $\mathbf{C}, 24 \mathrm{~h}$, Uh364 × Uh365 (wild-type cross); or B and D, after 48 h, Uh1011 $\times$ Uh1015 ( $\Delta$ cnal cross). Abbreviations: s, sporidia; $\mathrm{mh}$, mating hyphae; dh, dikaryotic hyphae. $\mathbf{C}$ and D, Septa are indicated by arrow heads. Scale bar: $10 \mu \mathrm{m}$. 
(Uh1216 × Uh1219, Uh1217 × Uh1229) or UhCnbl (Uh1105 $\times$ Uh1262; Uh1106 $\times$ Uh1263) genes, randomly integrated into the genome (Fig. 7, representative data).

\section{Effect on genes possibly regulated by the calcineurin pathway.}

The expression of genes involved in ion homeostasis is partly regulated through the calcineurin pathway in $\mathrm{U}$. hordei. In view of the increased sensitivity of calcineurin mutants to mono- or divalent cations, we investigated whether the calcineurin pathway regulates transcription of genes involved in maintenance of cell-ion homeostasis. Salt tolerance in yeast is orchestrated through the action of plasma membrane ATPases (Ena system), which are involved in $\mathrm{Na}^{+}$and $\mathrm{Li}^{+}$efflux (Ariño et al. 2010). Using the Ena1p, Ena2p, and Ena5p protein sequences from $S$. cerevisiae and the corresponding Enal proteins from $U$. maydis and Cryptococcus neoformans, several genes with similar annotations were retrieved from the $U$. hordei database. Two genes, UH_02598 and UH_00318, which had the highest similarity score and were annotated as ENA2 plasma membrane ATPase and $\mathrm{Ca}^{2+}$-transporting ATPase, respectively, were named UhEnal and UhEna2, respectively, following the nomenclature in $U$. maydis (Benito et al. 2009). We investigated their expression patterns by quantitative reverse-transcription (qRT)-PCR in the wild-type strain Uh365 and $\Delta$ cnal cells (Uh1015), grown in $\mathrm{CM}(\mathrm{pH}$ 7.3) medium with the addition of either $80 \mathrm{mM} \mathrm{LiCl}$ or $500 \mathrm{mM} \mathrm{NaCl}$. Both salt treatments induced the expression of both genes in wildtype cells, whereas their expression was reduced in $\Delta$ cnal cells (Fig. $8 \mathrm{~A}$ and B, representative data). The residual expression seen indicates the involvement of other signaling pathways as is observed in ENA1 from S. cerevisiae (Platara et al. 2006). It appears that both UhEnal and UhEna2 are induced upon salt stress in a calcineurin-dependent manner.

Regulation of cell-wall biosynthetic genes by the calcineurin pathway. Whatever the cause, the deletion of UhCnal or $U h C n b 1$ results in increased 1,3- $\beta$-D-glucan synthesis (discussed above). Therefore, we wanted to investigate whether the level of this polysaccharide quantified in calcineurin mutants could be correlated with the expression of genes involved in its synthesis. In $S$. cerevisiae, these processes are carried out by GAS1 (1,3- $\beta$-glucanosyltransferase) and FKS1 and FKS2 (1,3$\beta$-D-glucan synthase) (Lesage and Bussey 2006). Several fungal 1,3- $\beta$-glucanosyltransferase homologs to GAS1 were found at the National Center for Biotechnology Information (NCBI) and were used as queries against the $U$. hordei database. A sin-

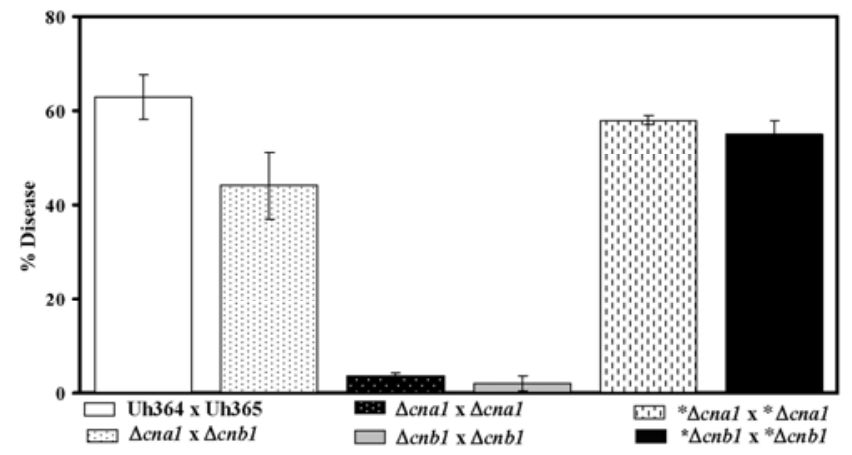

Fig. 7. Effect of calcineurin deletion on virulence. Barley seeds, cv. Odessa, were inoculated with a mixture of sexually compatible strains affected or not in the calcineurin-encoding genes. Disease symptoms were scored 2 months after inoculation. Results are the average of three independent experiments, conducted in duplo. Uh364 and Uh365, wild-type strains; $\Delta c n a 1$, Uh1011 or Uh1015; $\Delta c n b 1$ Uh1123 or Uh978; * $\Delta c n a l$ or $* \Delta c n b 1$ mutant strains complemented with wild-type UhCnal (Uh1220, Uh1216) or UhCnb1 (Uh1262, Uh1105) genes. gle gene, UH_02432, was identified as the putative UhGas1 homolog. According to our qRT-PCR data, UhGasl was upregulated in wild-type Uh365 cells grown in $\mathrm{CM}(\mathrm{pH} 7.3)$ amended with $500 \mathrm{mM} \mathrm{NaCl}$ for 30 min as compared with the control condition (Fig. 9A). However, the same change in expression level was seen for the $\Delta c n a l$ mutant when presented with the same saline stress, suggesting no regulation of UhGas 1 by the calcineurin pathway (Fig. 9A). On the other hand, UH_02430 was the only putative gene homolog found in the genome of $U$. hordei encoding the 1,3- $\beta$-D-glucan synthase (UhFks1). Similarly, one copy has been identified in the close relative to $U$. hordei, $U$. maydis (Ruiz-Herrera et al. 2008), whereas S. cerevisiae has two genes, FKS1 and FKS2, with essential, overlapping function (Mazur et al. 1995). When the same saline stress was applied to wild-type Uh365 cells, the expression of UhFksl was not significantly altered (Fig. 9B). However, in $\Delta c n a l$ calcineurin mutant cells, an induction of transcription was seen (Fig. 9B). In C. neoformans, impairment of the calcineurin pathway through deletion of $C N B 1$ or by FK506 addition highly induces the expression of FKSI under standard growing conditions (Kraus et al. 2003). In contrast, in B. cinerea which has only one FKS1 homolog, no significant difference in the expression of this gene was observed by deletion of the transcription factor $B c C R Z 1$ (Schumacher et al. 2008). In Magnaporthe oryzae, FKS1 expression was reduced by deletion of $M o C R Z 1$ in cells grown in $\mathrm{CaCl}_{2}$ (Choi et al. 2009) as well as in Candida albicans $\Delta$ cnal homozygous cells grown under several culture conditions (Sanglard et al. 2003). On the other hand, in $S$. cerevisiae, FKS2 expression is positively regulated by the calcineurin pathway (Zhao et al. 1998). Our data and data from the literature suggest that the calcineurin pathway is involved in the regulation of $U h F K S 1$, and its upregulation correlates with the observed increase in the amount of $1,3-\beta$-D-glucan quantified in the calcineurin mutants grown under salt stress imposed by $\mathrm{NaCl}$.
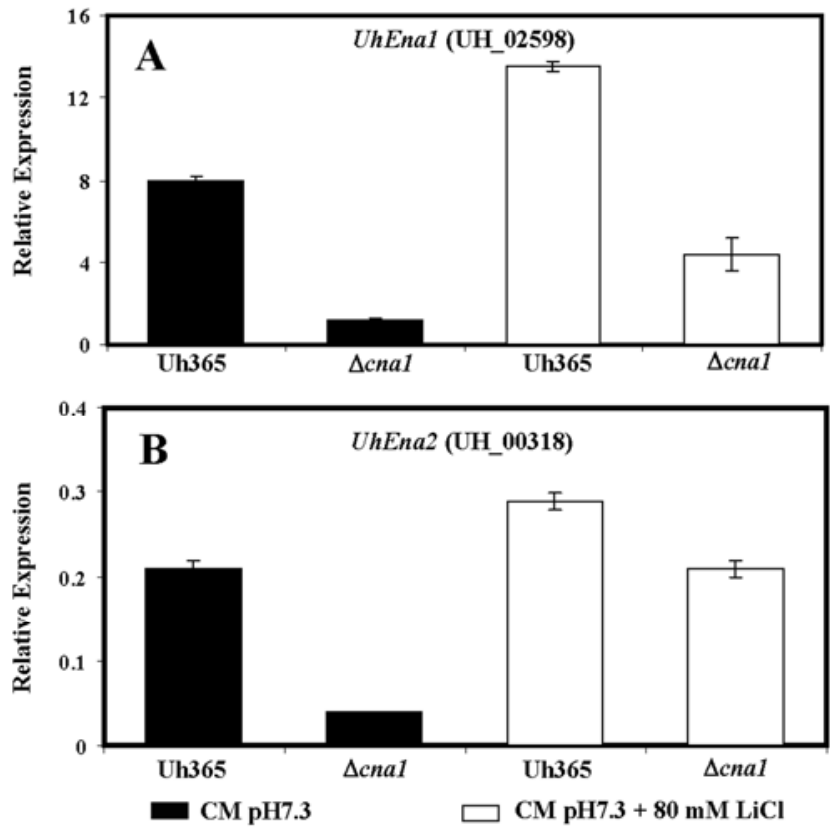

Fig. 8. Relative expression of UhEnal and UhEna2 genes. Strains Uh365 (wild type) and $\Delta$ cnal (Uh1015) were grown in liquid complete medium $(\mathrm{CM})$ at $22^{\circ} \mathrm{C}$ for $24 \mathrm{~h}$. Cells were collected and inoculated in liquid CM $(\mathrm{pH} 7.3)$ without or with $80 \mathrm{mM} \mathrm{LiCl}$. Cells were recovered after $1 \mathrm{~h}$ and RNA was purified. Expression levels of UhEnal and UhEna2 were analyzed by quantitative reverse-transcription polymerase chain reaction and normalized to the UhActin and UhelF $2 B$ reference genes. Error bars represent standard error of mean expression values. 
Rescue of mutant phenotypes.

Genetic complementation of calcineurin mutants. Strains Uh1011 and Uh1015 (Acnal MAT-1 or MAT-2) were each transformed with episomal plasmids Uh1223 or Uh1220 harboring the calcineurin catalytic subunit gene from $U$. hordei (e.g., Uh1094, Uh1095, Uh1099, and Uh1100) or its homolog from U. maydis (e.g., Uh1096, Uh1097, Uh1102, and Uh1103), respectively. Similarly, strains Uh1123 and Uh978 ( $\Delta c n b 1$ $M A T-1$ or $M A T-2)$ were transformed with integrative plasmid 1222 or episomal plasmid 1219 bearing the wild-type regulatory subunit gene from U. hordei (Uh1105, Uh1106, Uh1262, and Uh1263) or U. maydis (Uh1080 and Uh1081), respectively (Materials And Methods). Double resistant transformants (carboxin and hygromycin B or carboxin and Zeocin, depending on the complementing plasmid used) were selected on double CM plates supplemented with $1 \mathrm{M}$ sorbitol (DCM-S). Details on the genotypes of the set of complemented strains selected for further experiments are shown in Table 1.

All complemented deletion strains, whether harboring the $U$. hordei or the U. maydis complementing homolog, were undistinguishable from the wild-type $U$. hordei parental strains in colony or cellular morphology when grown on CM, YEPS, or PDB media (data not shown). The ability to grow as hyphae was recovered as well (data not shown). Complemented $U$. hordei deletion strains were able to grow in $\mathrm{CM}$ adjusted to $\mathrm{pH}$ 7.8 , as well as in media supplemented with $2 \%$ peptone. On $\mathrm{CM}$ (pH 7.3) supplemented with cell-wall-disturbing agents (0.002\% SDS, CR at $8.5 \mu \mathrm{g} \mathrm{ml}^{-1}, 0.5 \mathrm{mM}$ caffeine, CFW at 1 $\mu \mathrm{g} \mathrm{ml}{ }^{-1}$, or fludioxonil at $0.125 \mu \mathrm{g} \mathrm{ml}^{-1}$ ), all complemented strains were able to overcome the defects caused by the deletions (Supplementary Fig. S5; data not shown). The number of CFU recovered on media without osmotic support after cellwall digestion was also similar to that obtained from wild-type strains (data not shown). They were also able to grow on CM (pH 7.3) supplemented with monovalent cations $(30 \mathrm{mM} \mathrm{CsCl}$,
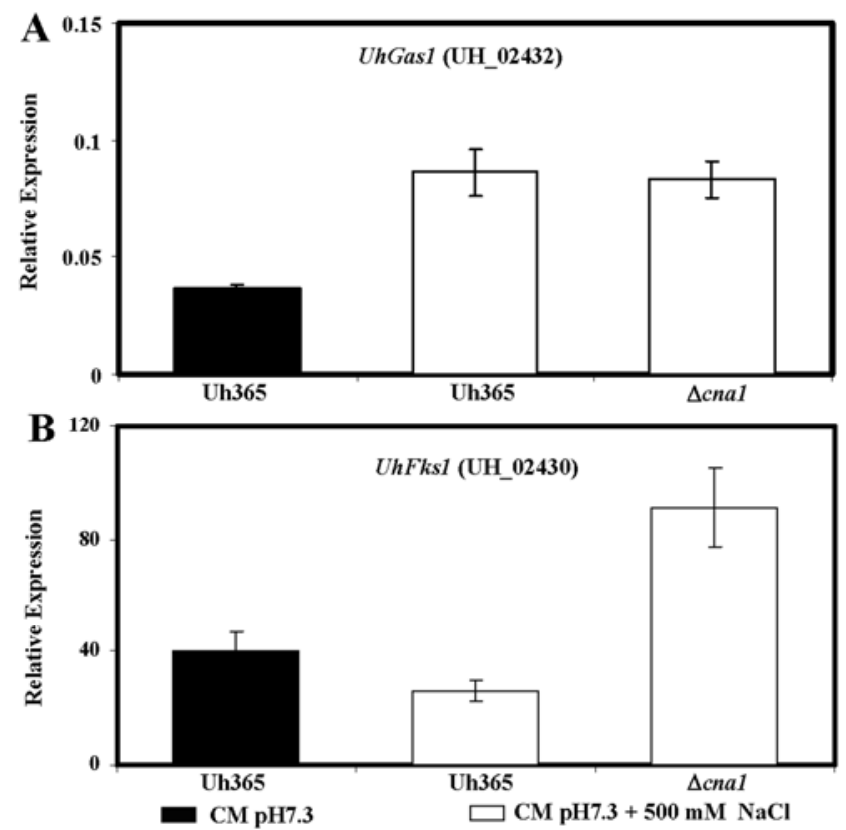

Fig. 9. Relative expression of UhFks1 and UhGas1 genes. Strains Uh365 (wild type) and $\Delta$ cnal (Uh1015) were grown in liquid complete medium (CM) at $22^{\circ} \mathrm{C}$ for $24 \mathrm{~h}$. Cells were collected and inoculated in liquid CM (pH 7.3) without or with $500 \mathrm{mM} \mathrm{NaCl}$. Cells were recovered after $30 \mathrm{~min}$ and RNA was purified. Relative expression levels of UhFks 1 and UhGas 1 were analyzed by quantitative reverse-transcription polymerase chain reaction and normalized to the UhActin and UhelF $2 B$ reference genes. Error bars represent standard error of mean expression values.
$30 \mathrm{mM} \mathrm{LiCl}$, or $600 \mathrm{mM} \mathrm{NaCl}$ ) or divalent cations $(30 \mathrm{mM}$ $\mathrm{MgCl}_{2}, 20 \mathrm{mM} \mathrm{MnCl}$, or $400 \mathrm{mM} \mathrm{CaCl}$ (data not shown). Complemented mutants survived equally well compared with wild-type cells after treatment with oxidative agents, UV light, or under acid conditions, as well as after enduring heat shock treatment $\left(39^{\circ} \mathrm{C}\right.$ for $\left.40 \mathrm{~min}\right)$ or continuous growth at $28^{\circ} \mathrm{C}$ (data not shown). When challenged by chemically induced ER stress conditions $(0.1 \mu \mathrm{M}$ Tm, 1 mM EGTA, or $50 \mu \mathrm{M}$ DTT), all complemented strains revealed a wild-type phenotype (Supplementary Fig. S6). Similarly, the presence of heavy metals in $\mathrm{CM}(\mathrm{pH} 7.3)\left(7 \mathrm{mM} \mathrm{ZnCl}, 15 \mathrm{mM} \mathrm{FeCl}{ }_{3}, 1 \mathrm{mM} \mathrm{NiNO}_{3}, 0.1\right.$ $\mathrm{mM} \mathrm{CrO}_{3}$, or $1 \mathrm{mM} \mathrm{CuCl}_{2}$ ) also did not cause growth inhibition in this set of complemented strains.

\section{DISCUSSION}

Recently, calcium signaling via the calcineurin pathway has been shown to play a role in fungal virulence toward human or plant hosts (Choi et al. 2009; Egan et al. 2009; Fox et al. 2001; Karababa et al. 2006; Schumacher et al. 2008). In the present study, through deletion of calcineurin-encoding genes UhCnal and $U h C n b 1$ in $U$. hordei, we analyzed the roles played by this pathway in this basidiomycete. We found that calcineurin mutants showed pleiotropic phenotypes being affected in several biological aspects involving environmental stresses and impacting on virulence, which was dramatically reduced. All phenotypes displayed by the $U$. hordei calcineurin mutants were alleviated to the same degree by the expression of Cnal and $C n b 1$ genes from $U$. hordei as well as the homologs from $U$. maydis. This not only confirmed that the phenotypes of the calcineurin mutants were caused by the impairment of UhCnal and $U h C n b l$ but also showed the conservation of gene functions in both species.

In yeast, CsA binds peptidyl-prolyl isomerase cyclophilin A, and this complex then targets calcineurin, resulting in cellgrowth inhibition (Cardenas et al. 1995). In general, abolishment of CsA binding by calcineurin/cyclophilin renders fungal cells resistant to the toxic effect of this calcineurin inhibitor (Cruz et al. 2000; da Silva Ferreira et al. 2007). However, our findings revealed a different scenario in $U$. hordei, considering the fact that deletion of calcineurin-encoding genes did not improve the tolerance to CsA's toxicity and calcineurin mutants were as sensitive as the wild-type strain. It is possible that the CsA-cyclophilin complex targets other proteins affecting downstream processes, resulting in cell growth arrest. Mutants lacking $B c C R Z 1$, a target of calcineurin in $B$. cinerea, are still able to respond to calcineurin inhibitors (CsA or FK506), resulting in growth reduction (Schumacher et al. 2008). To our knowledge, this is the first report in basidiomycetes (second in fungi) showing sensitivity of calcineurin deletion mutants to this compound, opening avenues to study CsA toxicity mechanisms which could be different among fungi.

The fungal cell wall is a well-organized structure subjected to an accurate remodeling process in response to stressful environmental conditions, and also during cell growth and development (Lesage and Bussey 2006). It has been documented that glucan and chitin are the most important polysaccharides used for its construction (Klis et al. 2006). Our study revealed that $U$. hordei calcineurin mutants were sensitive to several indicator compounds of compromised cell-wall integrity. $U$. hordei calcineurin mutants stressed by nonphysiological levels of $\mathrm{NaCl}$ produced increased amounts of $1,3-\beta$-D-glucan due to higher expression of the of the unique 1,3- $\beta$-D-glucan synthase gene present in $U$. hordei (UhFksl), suggesting a negative transcriptional regulatory mechanism by the calcineurin pathway. These data contrast with the regulation of the FKS1 homolog in $C$. albicans. In this fungus, a reduction of $F K S 1$ 
expression was scored in a calcineurin-dependent manner under several conditions tested (Sanglard et al. 2003). Similarly, a downregulation of the corresponding homologs in the ascomycetes $A$. fumigatus ( $f k s A$ ) and $M$. oryzae ( $F K S 1)$ was detected in cells growing in the presence of calcium, and calcineurin signaling was impaired by either genetic or chemical means (Cramer et al. 2008; Choi et al. 2009). It seems that different regulatory mechanisms for $F K S 1$ evolved in basidiomycetes, given that high expression of the corresponding homolog was also reported in a $\Delta c n b l$ mutant of Cryptococcus neoformans grown under standard conditions (Kraus et al. 2003). In $S$. cerevisiae, the synthesis of glucan and chitin is induced during cell stress and is mediated by the PKC and calcineurin pathways (Zhao et al. 1998). Similarly, in C. neoformans, mutants in the PKCl gene revealed an abnormal distribution of chitin and chitosan in addition to several phenotypes similar to our $U$. hordei calcineurin mutants (Gerik et al. 2008). Interestingly, a communication between PKC and the calcineurin pathway has been demonstrated in this human pathogen (Kraus et al. 2003). Although we only measured glucan content in the $U$. hordei calcineurin mutants, it is possible that differences in the chitin content or its distribution occurred as well, adding to the observed cell-wall defects to a certain extent. In general, chitin synthesis is a tightly regulated process. For example, in Candida albicans, such exquisite regulation proceeds through the coordinated function of $\mathrm{Ca}^{2+} /$ calcineurin, PKC, and HOG pathways (Munro et al. 2007); and, in A. fumigatus, recent evidence was presented for the regulation of chitin synthase genes orchestrated through the calcineurin pathway (Fortwendel et al. 2010).

Impairment of calcineurin signaling in fungi results in pleiotropic phenotypes, several of which might contribute to a reduction in virulence toward hosts. In the plant pathogen $B$. cinerea, deletion of $B c C R Z 1$, one of the targets of calcineurin, shows that it is required for full virulence (Schumacher et al. 2008). In this regard, two genes potentially coding for CRZ1 and, possibly, targets for calcineurin were identified in the $U$. hordei genome (data not shown), represented by $U$. maydis homologs um12004 and um10181. Several phenotypic traits are shared between $U$. hordei $\Delta c n a l$ and $\Delta c n b l$ and $B$. cinerea $\Delta B c c r z 1$ mutants, one of them being cell-wall defects. Bccrzl cells were unable to penetrate plant cells but reinforcement of the fungal cell wall by addition of $\mathrm{Mg}^{2+}$ restored this capability (Schumacher et al. 2008). The addition of $\mathrm{Mg}^{2+}$ did not improve the growth of $U$. hordei calcineurin mutants under any of the applied stresses tested (data not shown). The importance of cell-wall integrity during the infection process was recently demonstrated in $U$. maydis, where deletion of the chitin synthase $\mathrm{V}$ gene resulted in changes in cell-wall composition and mutants showed reduced infection in corn plants (Treitschke et al. 2010). Accumulation of certain cell-wall components or remodeling, including masking of pathogen-associated molecular pattern epitopes during infection, may help the pathogen to bypass the plant surveillance mechanism. $M$. grisea undergoes dynamic changes in cell-wall composition during the infection process and, indeed, preferential accumulation of $\alpha$-1,3-glucan protects the cell against the degradative effect of plant chitinase (Fujikawa et al. 2009). In light of revealed communication between the PKC1 mitogen-activated protein kinase (MAPK) signaling cascade and the calcineurin pathway in Cryptococcus neoformans (Kraus et al. 2003), it is possible that the $U$. hordei calcineurin mutants are more susceptible to cell-wall digestion by host digestive enzymes caused by a lack of interaction with the cell-wall integrity MAPK cascade. Indeed, $U$. hordei calcineurin mutants were more sensitive to cell-wall-degrading enzymes in vitro, and it is worth mentioning in this context that $U$. hordei calcineurin mutants were also sensitive to nitrosa- tive stress, similar to $C$. neoformans $\Delta p k c 1$ cells, which were also damaged by SDS, caffeine, CFW, or CR (Gerik et al. 2008). Another pleiotropic phenotype observed in the U. hordei calcineurin mutants, an increased sensitivity compared with wildtype cells toward reactive oxygen species (ROS) (produced in the presence of $\mathrm{RB}$ or by addition of $\mathrm{H}_{2} \mathrm{O}_{2}$ ), could also contribute to reduced virulence. Recognition of pathogens by host plants is often followed by ROS production (Nurnberger et al. 2004). We hypothesized that these mutants are not able to properly activate mechanism involved in ROS detoxification, normally allowing them to successfully infect their host. It has recently been shown that deletion mutants of $U$. maydis yap1, a transcription factor that protects cells against ROS damage, were sensitive to $\mathrm{H}_{2} \mathrm{O}_{2}$ and, as a consequence, were reduced in virulence owing to the cells being killed by the ROS produced by the host (Molina and Kahmann 2007).

Mating in Ustilago spp. is the prelude for several cellular processes that result in the establishment of disease, and we analyzed whether mating was affected in $U$. hordei calcineurin mutants. In a cross of MAT-1 $\triangle c n a 1 \times M A T-2 \triangle c n a 1$ or MAT-1 $\Delta c n b 1 \times M A T-2 \Delta c n b 1$, we observed that the response to mating pheromone was delayed but not abrogated in these haploid mutant cells. In the wild-type cross, cell conjugation occurred within $24 \mathrm{~h}$ whereas the same structures were observed, on average, $24 \mathrm{~h}$ later in the mutant cross. Because the disease rating achieved with $\Delta c n a l \times \Delta c n b l$ crosses was similar to wild-type infection, this revealed not only that each deletion was recessive but also that early steps leading to conjugation were occurring and that the wild-type gene harbored in the other mating partner complemented the deletion once mated (i.e., the dikaryotic cell). Mutants in the $U$. maydis calcineurin catalytic subunit gene, Ucnl, did not seem to mate in a lesssensitive plate mating assay (Egan et al. 2009). Similarly, $C$. neoformans mutants affected in $C N A 1$ or $C N B 1$ also revealed impaired mating (Cruz et al. 2001). Our experiments suggest that the reduction in virulence scored for the calcineurin mutants might be caused by post-mating events. This assumption is reinforced by data obtained in $U$. maydis, where this possibility was addressed by deletion of the Ucnl gene in the solopathogic strain SG200, in which the mating step is bypassed but a reduction in virulence similar to that observed for a cross with haploid mutants was obtained (Egan et al. 2009).

The importance of the Ena system in salt detoxification has been thoroughly addressed in S. cerevisiae (Ariño et al. 2010; Platara et al. 2006; Ruiz and Ariño 2007): exposure to high $\mathrm{NaCl}$ concentration in yeast leads to an intracellular calcium burst and a subsequent activating of the calcineurin pathway (Matsumoto et al. 2002). Given the sensitivity of the $U$. hordei calcineurin mutants to mono- or divalent cations, we analyzed the expression of the corresponding UhEnal and UhEna2 genes. According to our data, under salt stress, expression of both genes is positively regulated at the transcriptional level through the calcineurin pathway (Fig. 8), showing the importance of this system in ion detoxification in $U$. hordei as well. Benito and associates (2009) showed that expression of the corresponding $U$. maydis homologs, UmEnal and UmEna2, was induced by $\mathrm{NaCl}$ (and high $\mathrm{pH}$ ) in a fashion similar to $U$. hordei. In $S$. cerevisiae, expression of ENAl is regulated not only by $\mathrm{NaCl}$ but also by high pH (Serrano et al. 2002), and the homologous gene in Fusarium oxysporum is induced only when the two conditions are present together (high $\mathrm{pH}$ and $\mathrm{NaCl}$ ) (Caracuel et al. 2003). This indicates a complex regulation of this gene given that, in S. cerevisiae, ENA1 transcriptional regulation proceeds through the joint participation of several pathways, including calcium/calcineurin (Platara et al. 2006; Ruiz and Ariño 2007; Serrano et al. 2002). U. hordei $\Delta c n a l$ and $\Delta c n b l$ cells were highly sensitive to changes in the 
$\mathrm{pH}$ of the growth media (neutral to mildly alkaline), in contrast to $M$. oryzae cells deleted for the $M C N A$ gene (Choi et al. 2009) but similar to Candida albicans $\Delta$ cnal mutants (Bader et al. 2003) or Cryptococcus neoformans cells treated with calcineurin inhibitors (Odom et al. 1997). In fungi, adaptation to changes in environmental $\mathrm{pH}$ is mediated by the Rim101/PacC pathway (Peñalva et al. 2008), and impairment of this pathway in $U$. maydis renders mutants sensitive to alkaline $\mathrm{pH}$ and reveals pleiotropic defects that resemble the $U$. hordei calcineurin mutant phenotypes (Cervantes-Chávez et al. 2010).

In $U$. hordei, the calcineurin pathway plays a role in cell-wall construction and the adaptation to changes in the environment such as $\mathrm{pH}$, salinity, and many other stresses, including adjustment to the host environment upon infection. Our work and the mentioned related studies indicate that likely more than one pathway is required to orchestrate proper cell responses, and the paucity in the understanding of the interplay between the various signaling cascades deserves further examination. Studies should focus on establishing the link between calcineurin and other signaling cascades and, with regard to fungal pathogens, further elucidate the role of the calcineurin pathway in infection and disease progression.

\section{MATERIALS AND METHODS}

\section{Strain growth conditions.}

$U$. hordei haploid strains (Table 1) were preserved at $-80^{\circ} \mathrm{C}$ in liquid CM (Holliday 1961) supplemented with 9\% DMSO and were recovered on solid CM, or YEPS (1\% yeast extract, $2 \%$ peptone, $2 \%$ sucrose), incubated at $22^{\circ} \mathrm{C}$ for 3 days. $U$. hordei genetic transformation was achieved by making protoplasts according to (Barrett et al. 1993) using T. harzianum lysing enzymes (Sigma-Aldrich, St. Louis). Transformants were selected on hypertonic DCM-S plus carboxin $\left(2 \mu \mathrm{g} \mathrm{ml}^{-1}\right.$; Sigma-Aldrich), Zeocin (40 $\mu \mathrm{g} \mathrm{m}^{-1}$; Invitrogen, Valencia, CA, U.S.A.), or hygromycin B (120 $\mathrm{g} \mathrm{ml}^{-1}$; Calbiochem, La Jolla CA, U.S.A.) where appropriate. CsA, CFW, Tm, SDS, EGTA, A23187, DTT, laminarin, and fludioxonil were obtained from Sigma-Aldrich; acetic acid, $\mathrm{H}_{2} \mathrm{O}_{2}, \mathrm{RB}$, sodium nitrite $\left(\mathrm{NaNO}_{2}\right)$, and caffeine were obtained from Fluka. Escherichia coli DH5 $\alpha$ and DH10BR strains were used for routine plasmid propagation, cloning, and subcloning steps; transformation was performed by standard procedures (Sambrook and Russell 1999).

\section{Nucleic acid manipulation.}

Purification of genomic DNA for PCR was carried out according to Hoffman and Winston (1987). For DNA blots, genomic DNA was purified using the Qiagen plant genomic DNA extraction kit (Qiagen, Mississauga, Ontario, Canada). PCR was conducted using Taq polymerase or, when required, high fidelity Taq $P f x$ DNA polymerase (Invitrogen). Purification of PCR products for labeling or cloning reactions was carried out using the PCR purification Kit from Qiagen. Vector dephosphorylation, ligation, and DNA digestion were done according to suppliers' instructions (Invitrogen). Sequences of primers used are given in Table 2. Sequencing reactions were performed using the Big Dye terminator mix from Applied Biosystems and an ABI310 Genetic Analyzer (Foster City, CA, U.S.A.). For DNA blot hybridization, $10 \mu \mathrm{g}$ of genomic DNA was digested with selected restriction enzymes and run out in $1.1 \%$ agarose in Tris-acetate-EDTA buffer (40 mM Tris-acetate, $1 \mathrm{mM}$ EDTA) gels. Blotting to Nylon membranes (Amersham Biosciences, Buckinghamshire, U.K.) and hybridization were carried out following standard procedures (Sambrook and Russell 1999). DNA probes to identify U. hordei $\Delta c n a l$ and $\Delta c n b 1$ mutants, corresponding to their $3^{\prime}$ flank sequence, were synthesized by PCR as follows: for $\Delta c n a l$, primers 1321 and 1322 with plasmid 1178 as a template (discussed below); for $\Delta c n b 1$, primers 1317 and 1318 with plasmid 1176 as a template (discussed below). Probes were labeled with $\left[\alpha-{ }^{32} \mathrm{P}\right]$ dCTP using the random primer labeling system kit (Amersham Biosciences) according to manufacturer's recommendations.

\section{qRT-PCR analysis.}

$U$. hordei strains of interest were grown as indicated in each experiment. Total RNA ( $1 \mu \mathrm{g})$ was purified according to Jones and associates (1985) and treated with amplification-grade DNAseI (Invitrogen). First-strand cDNA was synthesized using the Dynamo SYBR green 2-step qRT-PCR kit from FINNZYMES following their recommendations. Samples were run on a Mx3000P qPCR instrument (Stratagene, La Jolla, CA, U.S.A.) and the PCR-amplification program involved $15 \mathrm{~min}$ at $95^{\circ} \mathrm{C}$; followed by 40 cycles of $30 \mathrm{~s}$ at $94^{\circ} \mathrm{C}, 30 \mathrm{~s}$ at $63^{\circ} \mathrm{C}$,

Table 2. Primer list ${ }^{\mathrm{a}}$

\begin{tabular}{|c|c|}
\hline Number & Sequence \\
\hline $1078 \mathrm{R}$ & ATCGCGGCCTCGACGTTTCC \\
\hline $1079 \mathrm{~F}$ & GACAGCCTATTGTGGCAGCC \\
\hline $1315 \mathrm{R}$ & AAAATAGGGATAACAGGGTAATGGTTCTTCCTTGCGATGAAA \\
\hline $1316 \mathrm{~F}$ & GGGGACAAGTTTGTACAAAAAAGCAGGCTATCATCTTTGCCGAGTATTGGG \\
\hline $1317 \mathrm{~F}$ & GGGGACCACTTTGTACAAGAAAGCTGGGTAGATTACCAGTTTTGTCCTGC \\
\hline $1318 \mathrm{R}$ & AAAAATTACCCTGTTATCCCTAGTGTTGTGGTGAGTGTGAGC \\
\hline $1321 \mathrm{~F}$ & GGGGACCACTTTGTACAAGAAAGCTGGGTATGAGCGGACAGTATACGGCA \\
\hline $1322 \mathrm{R}$ & AAAAATTACCCTGTTATCCCTAGAGCAGGAAATGCAAGGAAA \\
\hline $1344 \mathrm{~F}$ & AAAATAGGGATAACAGGGTAATCGTGCAGTGTCAGTCCAACT \\
\hline $1345 \mathrm{R}$ & GGGGACAAGTTTGTACAAAAAAGCAGGCTATGGCAAGGTGCAGAAACTCTC \\
\hline $1368 \mathrm{~F}$ & CTGGGGGTGGCACGACTGGAT \\
\hline $1369 \mathrm{R}$ & GTCCATCGCTTCTTCCTCCAT \\
\hline $1412 \mathrm{~F}$ & ggatggatccgcggccgcCGAAGCACATCAACGAACACA \\
\hline $1413 \mathrm{R}$ & caaaggatccgcggcegcCTGCTGGCGGCTCTGGTGGTAG \\
\hline $1416 \mathrm{~F}$ & cgaaggatccgcggccgeGCCGACGTCTGCTGGATGTGC \\
\hline $1417 \mathrm{R}$ & cttcggatcegcggccgcCCAGCTCTCGGCATACCTTTCT \\
\hline $1420 \mathrm{R}$ & ggtagcggccgcGTTGGACGACTGGCGAAAGA \\
\hline $1421 \mathrm{~F}$ & ggatgcggccgcAACACTCAACCCAGCCCACAC \\
\hline $1422 \mathrm{R}$ & ccctagatctCCTCGACAAGCGCGGACGAGACT \\
\hline $1423 \mathrm{~F}$ & cccetagatctTCGCCAACGCCAAAGCATTCT \\
\hline
\end{tabular}


and $30 \mathrm{~s}$ at $72^{\circ} \mathrm{C}$; followed by acquisition of a dissociation curve to test for product purity. Standard error presented was obtained on the basis of duplicate RT-PCR assays with two biological replicates analyzed. The level of gene expression was normalized to the $U$. hordei reference genes actin (UH_08813; primers 1604 and 1605) and the translation initiation factor UhelF2B, epsilon subunit (UH_07772, primers 1595 and 1596). Gene sequences were identified in the $U$. hordei genome database at the MIPS (collaborative project of R. Kahmann, J. Schirawski, and G. Bakkeren, unpublished). Other U. hordei genes for which expression levels were determined were a plasma membrane P-type ATPase, UhEnal (UH_02598, primers 1608 and 1069); UhEna2, related to a calcium-transporting ATPase (UH_00318, primers 1610 and 1611); UhFks1, 1,3- $\beta$-D-glucan synthase (UH_02430, primers 1589 and 1627); and UhGasl, glucanosyl transferase (UH_02432, primers 1628 and 1629). Primers sequences are shown in Supplementary Table S2 online.

\section{Plasmid constructs.}

To delete the U. hordei Cnal (UhCnal, UH_01405) and Cnbl (UhCnb1, UH_01914) genes, plasmids 1178 and 1176 were constructed, respectively, according to the DelsGate technology (García-Pedrajas et al. 2010). Briefly, 5' and 3' sequences flanking the UhCnal gene were amplified with primer pairs 1344-1345 and 1321-1322, respectively (Table 2). For UhCnb1, 5' and $3^{\prime}$ flanks were generated with primer pairs 1315-1316 and 1317-1318, respectively (Table 2). Genomic DNA from $U$. hordei strain Uh365 (Table 1) was used as a template in PCR reactions: the 5' and 3' flanks (PCR-amplified) were subsequently recombined into $\mathrm{pDnorCbx}$ vector (NCBI accession number EU360889) using BP Clonase enzyme (Invitrogen). Then, plasmids were linearized at the unique restriction site I-SceI using the corresponding enzyme from New England Biolabs (Beverly, MA, U.S.A.), and the DNA was precipitated and used for transformation of $U$. hor$d e i$ as indicated above. Putative transformants resistant to carboxin were recovered on DCM-S and were repurified on CM plus carboxin to confirm their resistance. Putative mutants were identified by PCR-based screening using primer pairs for $\Delta c n a l$ (1369 and 1078) or $\Delta c n b l$ (1368 and 1079). In both cases, the expected PCR products of approximately $2 \mathrm{~kb}$ were successfully amplified (data not shown). Deletions were confirmed by DNA blot analysis.

Plasmids to complement U. hordei Acnal mutants. Plasmid 1220, an episomal plasmid derivative from pHyg101 (Mayorga and Gold 1998), confers resistance to hygromycin B and was constructed to harbor the calcineurin catalytic subunit gene, Ucn1, from $U$. maydis (um00936; MIPS). The complementing gene fragment, including a 764-bp $5^{\prime}$ upstream promoter region, the 1,884-bp open reading frame (ORF), and 757-bp 3' downstream terminator sequence, was amplified by PCR with primers 1412 and 1413, which each had a BamHI and NotI restriction enzyme site at their $5^{\prime}$ termini (Table 2). The PCR product was digested with NotI and cloned into the unique NotI site of pHyg101.

Plasmid 1223, an episomal plasmid derivative from pHyg101, was constructed similarly to bear the UhCnal gene (UH_01405). The full-length gene (806-bp 5' flank, 1,890-bp ORF, 970-bp 3' flank) was amplified by PCR with primers 1420 and 1421 which each had a NotI restriction enzyme site at their $5^{\prime}$ termini, to allow cloning into the ditto restriction site of pHyg101. With the aim to obtain stable transformants to carry out the pathogenicity test, this plasmid was converted to an integrative one by digestion with $S s p$ I to eliminate the autonomous replication sequence element.

Plasmids to complement $\mathrm{U}$. hordei $\Delta c n b 1$ mutants. Plasmid 1219 is an episomal plasmid harboring the $U$. maydis $\mathrm{Cnbl}$ gene (um10226, MIPS; 946-bp 5' flank, 528-bp ORF, 865-bp $3^{\prime}$ flank), amplified with primers 1416 and 1417, which each have a BamHI and NotI restriction enzyme site at their $5^{\prime}$ termini. The PCR product was digested with BamHI and cloned into the ditto site of plasmid pHyg 101.

Plasmid 1222 is an integrative plasmid conferring resistance to the antibiotic phleomycin (bleomycin, zeomycin, or Zeocin) and bears the UhCnbl gene (UH_01914; 1,358-bp 5' flank, 528-bp ORF, 784-bp 3' flank), amplified with primers 1422 and 1423 , which each had a $B g l \mathrm{II}$ restriction enzyme site at their 5' termini. After amplification, the PCR product was digested with $B g l I I$ and cloned in the unique $B g l I I$ site of plasmid pUBleX1Int, between the $U$. maydis HSP70 promoter and terminator elements (Hu et al. 2007). All constructs generated during this study were verified by sequencing.

\section{Cell morphology and microscopy.}

Wild-type Uh364 or Uh365 and mutant strains Uh1011 and Uh1015 (Acnal) or Uh1123 and Uh978 $(\Delta c n b 1)$ were grown in $\mathrm{CM}$ plus amendments and incubated under standard growing conditions for $36 \mathrm{~h}$. The optical density at $600 \mathrm{~nm}\left(\mathrm{OD}_{600}\right)$ of the cultures was measured in a He $\lambda$ ios $\beta$ spectrophotometer (Thermo Spectronic) and was adjusted to 1.2. Next, $5 \mathrm{ml}$ of MM (Holliday 1961), adjusted to $\mathrm{pH} 3$ or 7 according to RuizHerrera and associates (1995), was inoculated with $100 \mu \mathrm{l}$ of the preculture. Tubes were incubated under standard conditions and cell morphology was scored after $32 \mathrm{~h}$. Photomicrographs of cells were taken using a Zeiss Axiophot microscope, using DIC optics and $\times 40$ magnification. Images were captured using a Nikon D700 digital camera and processed with Photoshop software (Adobe, San Jose, CA, U.S.A.).

\section{Mating test.}

Strains of interest were grown in CM plus amendments and incubated under standard growing conditions for $24 \mathrm{~h}$. The $\mathrm{OD}_{600}$ of the cultures was adjusted to 0.8 and cells of compatible mating type were mixed in a 1:1 proportion. Next, a microscope slide was covered with a thin layer of $1 \%$ agar in MM, $\mathrm{pH} \mathrm{7,} \mathrm{without} \mathrm{glucose,} \mathrm{and} 10 \mu \mathrm{l}$ of various dilutions of the cell mixture were spread on the solidified agar. The slides were incubated at $22^{\circ} \mathrm{C}$ in a petri dish with wet paper towels to keep the humidity. Mating reactions were scored after 24 and $48 \mathrm{~h}$ incubation using DIC optics as mentioned above. Experiments were conducted twice obtaining similar results.

\section{Pathogenicity assay.}

Strains were grown in CM plus amendments as above. The $\mathrm{OD}_{600}$ of the cultures was adjusted to 0.5 and mating-type compatible strains $(M A T-1 \times M A T-2)$ (Table 1) were mixed in a 1:1 proportion in $\mathrm{CM}$ and incubated for $12 \mathrm{~h}$ at $22^{\circ} \mathrm{C}$ with slow shaking $(75 \mathrm{rpm})$. Then, cells were collected by centrifugation and resuspended in $10 \mathrm{ml}$ of sterile distilled water. Seed of universal susceptible barley cv. Odessa, previously surface sterilized with $1 \%$ bleach solution, were submerged into the cell suspension and a vacuum of $20 \mathrm{lbs}$ was applied for $20 \mathrm{~min}$. Subsequently, the seed were drained and dried at RT for $24 \mathrm{~h}$, whereafter they were sown in general potting mix (ProMixBX). Plants were grown under controlled conditions, $24 \mathrm{~h}$ of continuous light at $25^{\circ} \mathrm{C}$, and were scored at heading (after approximately 2 months) for smut symptoms. Data shown are the average of three independent experiments, each conducted in duplo.

\section{Inhibition of calcineurin pathway and calcium ionophore (A23187) treatment.}

Strains were grown in liquid CM plus amendments for 1.5 days at $22^{\circ} \mathrm{C}$ under constant shaking. The $\mathrm{OD}_{600}$ of the cultures 
was adjusted to 0.8 and $120 \mu \mathrm{l}$ of each strain was spread with a wet cotton swab on solid $\mathrm{CM}(\mathrm{pH} 7.3)$ plates (adjusted with $100 \mathrm{mM}$ Tris- $\mathrm{HCl}$ ) for CsA treatment or in $\mathrm{CM}(\mathrm{pH} 7.3)$ amended with $300 \mathrm{mM} \mathrm{CaCl} 2$ for $\mathrm{A} 23187$ treatment. A filter paper disc $(0.6 \mathrm{~cm})$ with CsA (100 or $200 \mu \mathrm{g}$ dissolved in ethanol) or with A23187 (4.5 mM) dissolved in DMSO was placed in the center of the corresponding petri dish. Plates were incubated at $22^{\circ} \mathrm{C}$ for 4 days, after which the size of the growthinhibitory halo was measured. As a control, a disc with ethanol or DMSO was included and, for the A23187 treatment, no detrimental effect was observed in the calcineurin mutants by the presence of $\mathrm{CaCl}_{2}$. These experiments were repeated three times.

\section{Stress assays.}

Strains were grown and diluted as above. Then, 10-fold serial dilutions were prepared and $10 \mu \mathrm{l}$ of each dilution was spotted on $\mathrm{CM}$ ( $\mathrm{pH} 7.3$ ) plates amended with the compounds as indicated for each experiment; compounds were added after agar was cooled to $55^{\circ} \mathrm{C}$. For UV light treatment, cells were spotted as above and dried, after which UV light $\left(42 \mathrm{~J} \mathrm{~cm}^{-2}\right)$ was applied using a UVP HL-2000 Hybrilinker-Hybridization oven (UVP). To measure the response to acid, oxidative, or heat shock stresses, $1 \mathrm{ml}$ of culture $\left(\mathrm{OD}_{600}\right.$ of 0.8$)$ was treated with (17.4 mM) $\mathrm{H}_{2} \mathrm{O}_{2}$ for $25 \mathrm{~min},(161 \mathrm{mM})$ acetic acid for $90 \mathrm{~min}$, or incubated at $39^{\circ} \mathrm{C}$ for 40 min with shaking. Next, cells were diluted and spotted as above on $\mathrm{CM}$ plates, $\mathrm{pH}$ 7.3. Plates were incubated at $22^{\circ} \mathrm{C}$, or at $28^{\circ} \mathrm{C}$ for the suboptimal incubation temperature test, after which time they were photographed using a Nikon D700 digital camera. The cell-wall fragility analysis of $U$. hordei mutants was conducted as follows. Strains of interest were grown in CM. Then, cells were recovered by centrifugation and the number of cells was adjusted to $1 \times 10^{7}$ cells $\mathrm{ml}^{-1}$ in SCS buffer $(20 \mathrm{mM}$ sodium citrate, $\mathrm{pH}$ 5.8, and $1 \mathrm{M}$ sorbitol). T. harzianum (Sigma-Aldrich) lysing enzymes $(1.5 \mathrm{mg})$ was added, and the mixture was incubated with constant shaking at $22^{\circ} \mathrm{C}$ for $60 \mathrm{~min}$. Subsequently, cells were serially diluted in water and $100-\mu$ l aliquots of a $10^{-3}$ dilution were spread on freshly prepared $\mathrm{CM}(\mathrm{pH} 7.3)$ plates without osmotic support. Plates were incubated at $22^{\circ} \mathrm{C}$ for 4 to 6 days and the number of CFU counted. Data presented are the result of three independent assays.

\section{Quantification of 1,3- $\beta$-D-glucan content.}

$1,3-\beta$-D-glucan content was determined using aniline blue (AB) as reported by Shedletzky and associates (1997). Briefly, strains of interest were grown in $\mathrm{CM}$ under standard conditions for $24 \mathrm{~h}$. Next, $50 \mathrm{ml}$ of CM was inoculated with $1 \mathrm{ml}$ of preculture and incubated for $18 \mathrm{~h}$. Cells were recovered by centrifugation, cultured in $\mathrm{CM}(\mathrm{pH} 7.3)$ amended with 500 or $250 \mathrm{mM} \mathrm{NaCl}$, and incubated for $30 \mathrm{~min}$ or for $4 \mathrm{~h}$, respectively, as above. Control cells were incubated as above but no salt was added. Subsequently, cells were ground in liquid nitrogen and $50 \mathrm{mg}$ was mixed with $250 \mu \mathrm{l}$ of a $1 \mathrm{~N} \mathrm{NaOH}$ solution. The resulting mixture was incubated at $80^{\circ} \mathrm{C}$ for 40 min in a water bath. Three aliquots of $50 \mu \mathrm{l}$ each were withdrawn and mixed with $200 \mu \mathrm{l}$ of $\mathrm{AB}$ solution $(0.03 \% \mathrm{AB}, 0.18$ $\mathrm{N} \mathrm{HCl}, 0.98 \mathrm{M}$ glycine- $\mathrm{NaOH}, \mathrm{pH} 9.5)$ and incubated for 30 min at $52^{\circ} \mathrm{C}$, followed by a 30 -min incubation at $22^{\circ} \mathrm{C}$. Samples were placed in a 96-well fluorescence plate (Microlon; Greiner Bio-One, Solingen-Wald, Germany), whereafter the $1,3-\beta$-D-glucan content was quantified using a spectrofluorometer microtiter-plate reader (SpectraMAX GeminiEM; Molecular Devices, Menlo Park, CA, U.S.A.). Excitation and emission wavelengths were 400 and $460 \mathrm{~nm}$, respectively. Concentration of 1,3- $\beta$-D-glucan was expressed as micrograms of glucan per milligrams of fresh weight and was calculated on the basis of a standard curve prepared with laminarin. The results shown are the average of three independent experiments.

\section{ACKNOWLEDGMENTS}

We fully acknowledge the preliminary use of the as yet unpublished $\mathrm{U}$. hordei genome database at the MIPS, generated through a collaborative project with R. Kahmann, Max Planck Institute for Terrestrial Microbiology, Marburg, Germany and J. Schirawski, Georg-August-Universität Göttingen, Germany. We thank S. Gold for 'Delsgate' constructs, X. Song for guidance for qRT-PCR experiments, M. Gijzen for comments on the manuscript, and the Canadian Agricultural Bioproducts Innovation Program for funding for J. A. Cervantes-Chávez and G. Bakkeren.

\section{LITERATURE CITED}

Altschul, S. F., Madden, T. L., Schaffer, A. A., Zhang, J., Zhang, Z., Miller, W., and Lipman, D. J. 1997. Gapped BLAST and PSI-BLAST: A new generation of protein database search programs. Nucleic Acids Res. 25:3389-3402.

Arbelet, D., Malfatti, P., Simond-Cote, E., Fontaine, T., Desquilbet, L., Expert, D., Kunz, C., and Soulie, M. C. 2010. Disruption of the Bcchs3a chitin synthase gene in Botrytis cinerea is responsible for altered adhesion and overstimulation of host plant immunity. Mol. Plant-Microbe Interact. 23:1324-1334.

Ariño, J., Ramos, J., and Sychrova, H. 2010. Alkali metal cation transport and homeostasis in yeasts. Microbiol. Mol. Biol. Rev. 74:95-120.

Bader, T., Bodendorfer, B., Schroppel, K., and Morschhauser, J. 2003. Calcineurin is essential for virulence in Candida albicans. Infect. Immun. 71:5344-5354.

Bakkeren, G., Jiang, G., Warren, R. L., Butterfield, Y., Shin, H., Chiu, R., Linning, R., Schein, J., Lee, N., Hu, G., Kupfer, D. M., Tang, Y., Roe, B.A., Jones, S., Marra, M., and Kronstad, J. W. 2006. Mating factor linkage and genome evolution in basidiomycetous pathogens of cereals. Fungal Genet. Biol. 43:655-666.

Barrett, K. J., Gold, S. E., and Kronstad, J. W. 1993. Identification and complementation of a mutation to constitutive filamentous growth in Ustilago maydis. Mol. Plant-Microbe Interact. 6:274-283.

Benito, B., Garciadeblas, B., Perez-Martin, J., and Rodriguez-Navarro, A. 2009. Growth at high $\mathrm{pH}$ and sodium and potassium tolerance in media above the cytoplasmic pH depend on ENA ATPases in Ustilago maydis. Eukaryot. Cell 8:821-829.

Bonilla, M., and Cunningham, K. W. 2003. Mitogen-activated protein kinase stimulation of $\mathrm{Ca}(2+)$ signaling is required for survival of endoplasmic reticulum stress in yeast. Mol. Biol. Cell 14:4296-4305.

Bonilla, M., Nastase, K. K., and Cunningham, K. W. 2002. Essential role of calcineurin in response to endoplasmic reticulum stress. EMBO (Eur. Mol. Biol. Organ.) J. 21:2343-2353.

Bormann, J., and Tudzynski, P. 2009. Deletion of Mid1, a putative stretchactivated calcium channel in Claviceps purpurea, affects vegetative growth, cell wall synthesis and virulence. Microbiology 155:39223933

Brombacher, K., Fischer, B. B., Rufenacht, K., and Eggen, R. I. 2006. The role of Yap1p and Skn7p-mediated oxidative stress response in the defence of Saccharomyces cerevisiae against singlet oxygen. Yeast 23:741-750.

Caracuel, Z., Casanova, C., Roncero, M. I., Di Pietro, A., and Ramos, J. 2003. $\mathrm{pH}$ response transcription factor PacC controls salt stress tolerance and expression of the P-Type $\mathrm{Na}$-ATPase Ena1 in Fusarium oxysporum. Eukaryot. Cell 2:1246-1252.

Carafoli, E. 2005. Calcium a universal carrier of biological signals. Delivered on 3 July 2003 at the Special FEBS Meeting in Brussels. FEBS (Fed. Eur. Biochem. Soc.) J. 272:1073-1089.

Cardenas, M. E., Muir, R. S., Breuder, T., and Heitman, J. 1995. Targets of immunophilin-immunosuppressant complexes are distinct highly conserved regions of calcineurin A. EMBO (Eur. Mol. Biol. Organ.) J. 14:2772-2783.

Cervantes-Chávez, J. A., Ortiz-Castellanos, L., Tejeda-Sartorius, M., Gold, S., and Ruiz-Herrera, J. 2010. Functional analysis of the $\mathrm{pH}$ responsive pathway Pal/Rim in the phytopathogenic basidiomycete Ustilago maydis. Fungal Genet. Biol. 47:446-457.

Chang, P. K. 2008. Aspergillus parasiticus crzA, which encodes calcineurin response zinc-finger protein, is required for aflatoxin production under calcium stress. Int. J. Mol. Sci. 9:2027-2043.

Choi, J. H., Kim, Y., and Lee, Y. H. 2009. Functional analysis of MCNA, a gene encoding a catalytic subunit of calcineurin, in the rice blast fungus Magnaporthe oryzae. J. Microbiol. Biotechnol. 19:11-16.

Cramer, R. A., Jr., Perfect, B. Z., Pinchai, N., Park, S., Perlin, D. S., 
Asfaw, Y. G., Heitman, J., Perfect, J. R., and Steinbach, W. J. 2008. Calcineurin target CrzA regulates conidial germination, hyphal growth, and pathogenesis of Aspergillus fumigatus. Eukaryot. Cell 7:1085-1097.

Cruz, M. C., Fox, D. S., and Heitman, J. 2001. Calcineurin is required for hyphal elongation during mating and haploid fruiting in Cryptococcus neoformans. EMBO (Eur. Mol. Biol. Organ.) J. 20:1020-1032.

Cyert, M. S. 2001. Genetic analysis of calmodulin and its targets in Saccharomyces cerevisiae. Annu. Rev. Genet. 35:647-672.

Cyert, M. S. 2003. Calcineurin signaling in Saccharomyces cerevisiae: How yeast go crazy in response to stress. Biochem. Biophys. Res. Commun. 311:1143-1150.

da Silva Ferreira, M. E., Heinekamp, T., Hartl, A., Brakhage, A. A., Semighini, C. P., Harris, S. D., Savoldi, M., de Gouvea, P. F., de Souza Goldman, M. H., and Goldman, G. H. 2007. Functional characterization of the Aspergillus fumigatus calcineurin. Fungal Genet. Biol. 44:219-230.

Egan, J. D., García-Pedrajas, M. D., Andrews, D. L., and Gold, S. E. 2009. Calcineurin is an antagonist to PKA protein phosphorylation required for postmating filamentation and virulence, while PP2A is required for viability in Ustilago maydis. Mol. Plant-Microbe Interact. 22:12931301.

Fan, W., Idnurm, A., Breger, J., Mylonakis, E., and Heitman, J. 2007. Eca1, a sarcoplasmic/endoplasmic reticulum $\mathrm{Ca}^{2+}$-ATPase, is involved in stress tolerance and virulence in Cryptococcus neoformans. Infect. Immun. 75:3394-3405.

Fisher, G W., and Holton, C. S. 1957. Biology and Control of the Smut Fungi. Ronald Press, New York.

Fortwendel, J. R., Juvvadi, P. R., Perfect, B. Z., Rogg, L. E., Perfect, J. R., and Steinbach, W. J. 2010. Transcriptional regulation of chitin synthases by calcineurin controls paradoxical growth of Aspergillus fumigatus in response to caspofungin. Antimicrob. Agents Chemother. 54:1555-1563.

Fox, D. S., Cruz, M. C., Sia, R. A., Ke, H., Cox, G. M., Cardenas, M. E., and Heitman, J. 2001. Calcineurin regulatory subunit is essential for virulence and mediates interactions with FKBP12-FK506 in Cryptococcus neoformans. Mol. Microbiol. 39:835-849.

Fujikawa, T., Kuga, Y., Yano, S., Yoshimi, A., Tachiki, T., Abe, K., and Nishimura, M. 2009. Dynamics of cell wall components of Magnaporthe grisea during infectious structure development. Mol. Microbiol. 73:553-570.

García-Pedrajas, M. D., Nadal, M., Denny, T., Baeza-Montanez, L., Paz, Z., and Gold, S. E. 2010. DelsGate: A robust and rapid method for gene deletion. Methods Mol. Biol. 638:55-76.

Gerik, K. J., Bhimireddy, S. R., Ryerse, J. S., Specht, C. A., and Lodge, J. K. 2008. PKC1 is essential for protection against both oxidative and nitrosative stresses, cell integrity, and normal manifestation of virulence factors in the pathogenic fungus Cryptococcus neoformans. Eukaryot. Cell 7:1685-1698.

Harel, A., Bercovich, S., and Yarden, O. 2006. Calcineurin is required for sclerotial development and pathogenicity of Sclerotinia sclerotiorum in an oxalic acid-independent manner. Mol. Plant-Microbe Interact. 19:682-693.

Hoffman, C. S., and Winston, F. 1987. A ten-minute DNA preparation from yeast efficiently releases autonomous plasmids for transformation of Escherichia coli. Gene 57:267-272.

Holliday, R. 1961. The genetics of Ustilago maydis. Genet. Res. 2:203230.

Hu, G., Kamp, A., Linning, R., Naik, S., and Bakkeren, G. 2007. Complementation of Ustilago maydis MAPK mutants by a wheat leaf rust, Puccinia triticina homolog: Potential for functional analyses of rust genes. Mol. Plant-Microbe Interact. 20:637-647.

Hu, G. G., Linning, R., and Bakkeren, G. 2002. Sporidial mating and infection process of the smut fungus, Ustilago hordei, in susceptible barley. Can. J. Bot. 80:1103-1114.

Jamsa, E., Simonen, M., and Makarow, M. 1994. Selective retention of secretory proteins in the yeast endoplasmic reticulum by treatment of cells with a reducing agent. Yeast 10:355-370.

Jones, J. D. G., Dunsmuir P., and Bedbrook, J. 1985. High level expression of introduced chimeric genes in regenerated transformed plants. EMBO (Eur. Mol. Biol. Organ.) J. 4:2411-2418.

Joubert, A., Bataille-Simoneau, N., Campion, C., Guillemette, T., Hudhomme, P., Lacomi-Vasilescu, B., Leroy, T., Pochon, S., Poupard, P., and Simoneau, P. 2010. Cell wall integrity and high osmolarity glycerol pathways are required for adaptation of Alternaria brassicicola to cell wall stress caused by brassicaceous indolic phytoalexins. Cell Microbiol. DOI:10.1111/j.1462-5822.2010.01520.x. Published online ahead of print.

Karababa, M., Valentino, E., Pardini, G., Coste, A. T., Bille, J., and Sanglard, D. 2006. CRZ1, a target of the calcineurin pathway in Candida albicans. Mol. Microbiol. 59:1429-1451.

Kissinger, C. R., Parge, H. E., Knighton, D. R., Lewis, C. T., Pelletier, L. A., Tempczyk, A., Kalish, V. J., Tucker, K. D., Showalter, R. E.,
Moomaw, E. W., Gastinel, L.N., Habuka, N., Chen, X., Maldonado, F. Barker, J. E., Bacquet, R., and Villafranca, J. E. 1995. Crystal structures of human calcineurin and the human FKBP12-FK506-calcineurin complex. Nature 378:641-644.

Klippel, N., Shuna, C., Lothar, G., and Bilitewski, U. 2010. Deletion of Candida albicans histidine kinase $C H K 1$ improves recognition by phagocytes through an increased exposure of cell wall $\beta$-1,3-glucans. Microbiology 156:3432-3444

Klis, F. M., Boorsma, A., and De Groot, P. W. 2006. Cell wall construction in Saccharomyces cerevisiae. Yeast 23:185-202.

Kojima, K., Bahn, Y. S., and Heitman, J. 2006. Calcineurin, Mpk1 and Hog1 MAPK pathways independently control fludioxonil antifungal sensitivity in Cryptococcus neoformans. Microbiology 152:591-604.

Kraus, P. R., and Heitman, J. 2003. Coping with stress: Calmodulin and calcineurin in model and pathogenic fungi. Biochem. Biophys. Res. Commun. 311:1151-1157.

Kraus, P. R., Fox, D. S., Cox, G. M., and Heitman, J. 2003. The Cryptococcus neoformans MAP kinase Mpk1 regulates cell integrity in response to antifungal drugs and loss of calcineurin function. Mol. Microbiol. 48:1377-1387.

Kukuruzinska, M. A., and Lennon, K. 1995. Diminished activity of the first N-glycosylation enzyme, dolichol-P-dependent N-acetylglucosamine-1-P transferase (GPT), gives rise to mutant phenotypes in yeast. Biochim. Biophys. Acta 1247:51-59.

Laurie, J. D., Linning, R., and Bakkeren, G. 2008. Hallmarks of RNA silencing are found in the smut fungus Ustilago hordei but not in its close relative Ustilago maydis. Curr. Genet. 53:49-58.

Lesage, G., and Bussey, H. 2006. Cell wall assembly in Saccharomyces cerevisiae. Microbiol. Mol. Biol. Rev. 70:317-343.

Linning, R., Lin, D., Lee, N., Abdennadher, M., Gaudet, D., Thomas, P., Mills, D., Kronstad, J. W., and Bakkeren, G. 2004. Marker-based cloning of the region containing the UhAvrl avirulence gene from the basidiomycete barley pathogen Ustilago hordei. Genetics 166:99-111.

Matheos, D. P., Kingsbury, T. J., Ahsan, U. S., and Cunningham, K. W. 1997. Tcn1p/Crz1p, a calcineurin-dependent transcription factor that differentially regulates gene expression in Saccharomyces cerevisiae. Genes Dev. 11:3445-3458.

Matsuda, S., and Koyasu, S. 2000. Mechanisms of action of cyclosporine. Immunopharmacology 47:119-125.

Matsumoto, T. K., Ellsmore, A. J., Cessna, S. G., Low, P. S., Pardo, J. M., Bressan, R. A., and Hasegawa, P. M. 2002. An osmotically induced cytosolic $\mathrm{Ca}^{2+}$ transient activates calcineurin signaling to mediate ion homeostasis and salt tolerance of Saccharomyces cerevisiae. J. Biol. Chem. 277:33075-33080.

Mayorga, M. E., and Gold, S. E. 1998. Characterization and molecular genetic complementation of mutants affecting dimorphism in the fungus Ustilago maydis. Fungal Genet. Biol. 24 364-376.

Mazur, P., Morin, N., Baginsky, W., el-Sherbeini, M., Clemas, J. A., Nielsen, J. B., and Foor, F. 1995. Differential expression and function of two homologous subunits of yeast 1,3- $\beta$-D-glucan synthase. Mol. Cell Biol. 15:5671-5681.

Meldolesi, J., and Pozzan, T. 1998. The endoplasmic reticulum $\mathrm{Ca}^{2+}$ store: A view from the lumen. Trends Biochem. Sci. 23:10-14.

Mendoza, I., Quintero, F. J., Bressan, R. A., Hasegawa, P. M., and Pardo, J. M. 1996. Activated calcineurin confers high tolerance to ion stress and alters the budding pattern and cell morphology of yeast cells. J. Biol. Chem. 271:23061-23067.

Miyakawa, T., and Mizunuma, M. 2007. Physiological roles of calcineurin in Saccharomyces cerevisiae with special emphasis on its roles in $\mathrm{G} 2 / \mathrm{M}$ cell-cycle regulation. Biosci. Biotechnol. Biochem. 71:633-645.

Molina, L., and Kahmann, R. 2007. An Ustilago maydis gene involved in $\mathrm{H}_{2} \mathrm{O}_{2}$ detoxification is required for virulence. Plant Cell 19:2293-2309.

Munro, C. A., Selvaggini, S., de Bruijn, I., Walker, L., Lenardon, M. D., Gerssen, B., Milne, S., Brown, A. J., and Gow, N. A. 2007. The PKC, HOG and $\mathrm{Ca}^{2+}$ signalling pathways co-ordinately regulate chitin synthesis in Candida albicans. Mol. Microbiol. 63:1399-1413.

Nurnberger, T., Brunner, F., Kemmerling, B., and Piater, L. 2004. Innate immunity in plants and animals: Striking similarities and obvious differences. Immunol. Rev. 198:249-266.

Odom, A., Del Poeta, M., Perfect, J., and Heitman, J. 1997. The immunosuppressant FK506 and its nonimmunosuppressive analog L-685,818 are toxic to Cryptococcus neoformans by inhibition of a common target protein. Antimicrob. Agents Chemother. 41:156-161.

Peñalva, M. A., Tilburn, J., Bignell, E., and Arst, H. N., Jr. 2008. Ambient $\mathrm{pH}$ gene regulation in fungi: Making connections. Trends Microbiol. 16:291-300.

Platara, M., Ruiz, A., Serrano, R., Palomino, A., Moreno, F., and Ariño, J. 2006. The transcriptional response of the yeast $\mathrm{Na(+)-ATPase} \mathrm{ENAI}$ gene to alkaline stress involves three main signaling pathways. J. Biol. Chem. 281:36632-36642. 
Ruiz, A., and Ariño, J. 2007. Function and regulation of the Saccharomyces cerevisiae ENA sodium ATPase system. Eukaryot. Cell 6:2175-2183.

Ruiz-Herrera, J., León, C., Guevara-Olvera, L., and Carabez-Trejo, A 1995. Yeast-mycelial dimorphism of haploid and diploid strains of Ustilago maydis. Microbiology 141:695-703.

Ruiz-Herrera, J., Ortiz-Castellanos, L., Martinez, A. I., León-Ramírez, C., and Sentandreu, R. 2008. Analysis of the proteins involved in the structure and synthesis of the cell wall of Ustilago maydis. Fungal Genet. Biol. 45 (Suppl. 1):S71-76.

Sambrook, J., and Russell, D. W. 1999. Molecular Cloning: A Laboratory Manual, 3rd. ed. Cold Spring Harbor Laboratory Press, Cold Spring Harbor, NY, U.S.A.

Sanglard, D., Ischer, F., Marchetti, O., Entenza, J., and Bille, J. 2003. Calcineurin A of Candida albicans: Involvement in antifungal tolerance, cell morphogenesis and virulence. Mol. Microbiol. 48:959-976.

Schumacher, J., de Larrinoa, I. F., and Tudzynski, B. 2008. Calcineurinresponsive zinc finger transcription factor CRZ1 of Botrytis cinerea is required for growth, development, and full virulence on bean plants. Eukaryot. Cell 7:584-601.

Serrano, R., Ruiz, A., Bernal, D., Chambers, J. R., and Ariño, J. 2002. The transcriptional response to alkaline $\mathrm{pH}$ in Saccharomyces cerevisiae: Evidence of calcium-mediate signalling. Mol. Microbiol. 46:13191333.

Shedletzky, E., Unger, C., and Delmer, D. P. 1997. A microtiter-based fluorescence assay for (1,3)- $\beta$-glucan synthases. Anal. Biochem. 249:88-93.

Stathopoulos, A. M., and Cyert, M. S. 1997. Calcineurin acts through the
$C R Z 1 / T C N 1$-encoded transcription factor to regulate gene expression in yeast. Genes Dev. 11:3432-3444.

Steinbach, W. J., Cramer, R. A., Jr., Perfect, B. Z., Asfaw, Y. G., Sauer, T.C., Najvar, L. K., Kirkpatrick, W. R., Patterson, T. F., Benjamin, D. K., Jr., Heitman, J., and Perfect, J. R. 2006. Calcineurin controls growth, morphology, and pathogenicity in Aspergillus fumigatus. Eukaryot. Cell 5:1091-1103.

Stie, J., and Fox, D. 2008. Calcineurin regulation in fungi and beyond. Eukaryot. Cell 7:177-186.

Treitschke, S., Doehlemann, G., Schuster, M., and Steinberg, G. 2010. The myosin motor domain of fungal chitin synthase $\mathrm{v}$ is dispensable for vesicle motility but required for virulence of the maize pathogen Ustilago maydis. Plant Cell 22:2476:2494.

Zhang, H., Zhao, Q., Liu, K., Zhang, Z., Wang, Y., and Zheng, X. 2009. $M g C R Z 1$, a transcription factor of Magnaporthe grisea, controls growth, development and is involved in full virulence. FEMS (Fed. Eur. Microbiol. Soc.) Microbiol. Lett. 293:160-169.

Zhao, C., Jung, U. S., Garrett-Engele, P., Roe, T., Cyert, M. S., and Levin, D. E. 1998. Temperature-induced expression of yeast FKS2 is under the dual control of protein kinase $\mathrm{C}$ and calcineurin. Mol. Cell Biol. 18:1013-1022.

\section{AUTHOR-RECOMMENDED INTERNET RESOURCE}

MIPS Fungal Genomics Group website: www.helmholtz-muenchen.de/en/mips/projects/fungi/index.html 